\title{
Xanthomonas Filamentous Hemagglutinin-Like Protein Fha1 Interacts with Pepper Hypersensitive-Induced Reaction Protein CaHIR1 and Functions as a Virulence Factor in Host Plants
}

\author{
Hyong Woo Choi, ${ }^{1}$ Dae Sung Kim, ${ }^{1}$ Nak Hyun Kim, ${ }^{1}$ Ho Won Jung, ${ }^{2}$ Jong Hyun Ham, ${ }^{3}$ and \\ Byung Kook Hwang' \\ ${ }^{1}$ Laboratory of Molecular Plant Pathology, College of Life Sciences and Biotechnology, Korea University, Anam-dong, \\ Sungbuk-ku, Seoul 136-713, Republic of Korea; ${ }^{2}$ Department of Genetic Engineering, College of Natural Resources and \\ Life Science, Dong-A University, Busan 604-714, Republic of Korea; ${ }^{3}$ Department of Plant Pathology and Crop Physiology, \\ Louisiana State University Agriculture Center, Baton Rouge, LA 70803, U.S.A.
}

Submitted 22 July 2013. Accepted 25 July 2013.

Pathogens have evolved a variety of virulence factors to infect host plants successfully. We previously identified the pepper plasma-membrane-resident hypersensitive-induced reaction protein (CaHIR1) as a regulator of plant diseaseand immunity-associated cell death. Here, we identified the small filamentous hemagglutinin-like protein (Fha1) of Xanthomonas campestris pv. vesicatoria as an interacting partner of CaHIR1 using yeast two-hybrid screening. Coimmunoprecipitation and bimolecular fluorescence complementation experiments revealed that Fha1 specifically interacts with CaHIR1 in planta. The endocytic tracker FM4-64 staining showed that the CaHIR1-Fha1 complex localizes in the endocytic vesicle-like structure. The $X$. campestris pv. vesicatoria $\Delta$ fhal mutant strain exhibited significantly increased surface adherence but reduced swarming motility. Mutation of fhal inhibited the growth of $X$. campestris pv. vesicatoria and $X$. campestris pv. vesicatoria $\triangle a v r B s T$ in tomato and pepper leaves, respectively, suggesting that Fha1 acts as a virulence factor in host plants. Transient expression of fhal and also infiltration with purified Fha1 proteins induced disease-associated cell death response through the interaction with CaHIR1 and suppressed the expression of pathogenesis-related (PR) genes. Silencing of $\mathrm{CaHIRI}$ in pepper significantly reduced $\triangle a v r B s T$ growth and Fha1-triggered susceptibility cell death.

Sequence data from this article can be found in the EMBL/GenBank data libraries under accession numbers KC466081 (fhal), AF053343 (CaPR1), AF442388 (CaDEF1), AY529867 (CaHIR1), Y08804 Senu4 (PR1), NM_001247943 Tgas $(D E F), \quad$ NM_001247203 Cevi16 (POX), and At4g05320 (UBQ).

Corresponding author: B. K. Hwang; Telephone: +82-32903061; Fax: +82-9211715; E-mail: bkhwang@korea.ac.kr

Current address of H. W. Choi: Boyce Thompson Institute for Plant Research, Tower Road Ithaca, NY 14853-1801, U.S.A.

Nucleotide sequence data of $X c v F H A 1$ from this article can be found in the GenBank data libraries under accession number KC466081.

* The $\boldsymbol{e}$-Xtra logo stands for "electronic extra" and indicates that seven supplementary figures and one supplementary table are published online and that Figures 1, 2, 4, 5, 6, 7, 9, and 10 appear in color online.

(C) 2013 The American Phytopathological Society
Overexpression of fhal in Arabidopsis retarded plant growth and triggered disease-associated cell death, resulting in altered disease susceptibility. Taken together, these results suggest that the $X$. campestris pv. vesicatoria virulence factor Fha1 interacts with CaHIR1, induces susceptibility cell death, and suppresses $P R$ gene expression in host plants.

Disease resistance is genetically controlled by pathogenderived effector proteins and their cognate resistance (R) proteins of host plants (Bent and Mackey 2007; Chisholm et al. 2006; Flor 1971; Jones and Dangl 2006). In effector-triggered immunity (ETI), R proteins recognize an invading pathogen and trigger resistance responses by directly detecting effector proteins or monitoring effector-induced modification of guardee proteins (Jones and Dangl 2006). ETI occurs in a cultivar- and race-specific manner. The recognition of general elicitors, which are known as pathogen-associated molecular patterns (PAMPs), induces PAMP-triggered immunity (PTI) in plants (Altenbach and Robatzek 2007; Bent and Mackey 2007). PAMPs are conserved structures of microbes that are essential for their life. The PAMPs include lipopolysaccharides (LPS) of bacteria, chitins of fungi, and $\beta$-glucans of oomycetes, among others (Altenbach and Robatzek 2007; Klarzynski et al. 2000). Unlike ETI, PTI occurs in different cultivars of one or many species. Recent studies show that the innate immune response is mediated by recognition of PAMP molecules by plasma membrane (PM)-resident pattern recognition receptors (PRR) (Altenbach and Robatzek 2007; Zipfel 2008). An extensively studied PTI response is FLAGELLIN SENSITIVE 2 (FLS2) receptor kinase-mediated flagellin recognition, which involves the highly conserved flg22 peptide (Chinchilla et al. 2006; Gómez-Gómez et al. 2001; Robatzek et al. 2006). However, few PRR recognizing PAMPs have been characterized in plants.

In animal systems, several PAMPs, such as glucans, chitin, LPS, and flagellin, are also known to activate PTI (Gordon 2002; Nürnberger et al. 2004). The filamentous hemagglutinin (Fha) protein of the whooping cough agent Bordetella pertussis was reported to interact with macrophage complement receptor 3 (CR3) (Ishibashi et al. 1994; Relman et al. 1990). Activation and surface expression of CR3 is important for Fha-mediated phagocytosis and subsequent killing of pathogens (Mobberley- 
Schuman and Weiss 2005; Weigart and Weiss 2000). Furthermore, vaccination with purified Fha proteins confers protection against $B$. pertussis and B. bronchiseptica in humans and mice, respectively (Goebel et al. 2009; Rieber et al. 2008). These findings suggest that the Fha protein, similar to other PAMPs, can activate immune responses in animal systems. The Fha proteins of gram-negative bacteria function as an adhesin and are highly conserved in their structure at the species level (Link et al. 2007). The well-known Fha protein of B. pertussis FhaB has at least three different binding activities, including carbohydrate binding, heparan sulfate binding, and integrin CR3 binding through its Arg-Gly-Asp (RGD) site (Ishibashi et al. 1994; Relman et al. 1990). These binding activities allow the pathogen to adhere to a variety of cells and extracellular structures in the respiratory epithelium. In particular, interaction of FhaB of $B$. pertussis with the macrophage CR3 implicates Fha in the competitive blockade of CR3-mediated leukocyte signal transduction, the delivery of bacterial toxins to host leukocytes, and bacterial intracellular entry for survival and persistence (Ishibashi et al. 1994; Relman et al. 1990). These findings suggest that the bacterial adhesin Fha not only plays a role in disarming the neutrophil defense mechanism but also can act as target protein of CR3-mediated phagocytosis in animal defense responses.

The role of Fha proteins of plant bacterial pathogens has mainly been studied on the basis of their virulence (Gottig et al. 2009; Guilhabert and Kirkpatrick 2005; Rojas et al. 2002). Two functional homologs of $B$. pertussis $F h a B$ were identified from Erwinia chrysanthemi and Xanthomonas axonopodis pv. citri (Gottig et al. 2009; Rojas et al. 2002). Mutation of FhaB homologs in these pathogens decreased their ability to adhere to plant tissues, leading to reduced virulence. In another study, screening of a random transposon (Tn5) mutant library of $X y$ lella fastidiosa revealed that the hemagglutinin adhesin gene $H x f B$ functions in bacterial cell-to-cell aggregation, which results in colony formation and biofilm maturation within the xylem vessels of grapevine (Guilhabert and Kirkpatrick 2005). These findings suggest that Fha proteins of plant pathogens function as virulence factors by modulating surface attachment, biofilm formation, and cell-to-cell aggregation during pathogenesis. However, whether these Fha proteins are able to elicit plant defense responses or whether the target proteins of Fha exist in plants remains to be determined.

In our previous study, the Capsicum annum hypersensitive induced reaction 1 (CaHIR1) protein was identified as a positive regulator of pathogen-induced cell death associated with disease and immunity (Choi et al. 2011; Jung and Hwang 2007; Jung et al. 2008). Expression of CaHIRl induced pathogen-independent callose deposition and hypersensitive-like cell death, accompanied by suppression of endogenous salicylic acid accumulation. Its cellular interacting protein $C$. annum leucinerich repeat 1 (CaLRR1) also antagonistically modulated CaHIR1 function in the execution of cell death (Choi et al. 2011; Jung et al. 2004; Jung and Hwang 2007). Interestingly, extracellular localized CaLRR1 interacted with PM-associated CaHIR1 to form membrane microdomains that may function as platforms for membrane transport, membrane trafficking, and cytoskeleton interaction (Browman et al. 2007). To identify pathogen-derived molecular partners recognized by CaHIR1, we screened a Xanthomonas campestris pv. vesicatoria GAL4 yeast two-hybrid (Y2H) prey library using CaHIR1 as bait. Here, we identified a small Fha-like protein, Fha1, of $X$. campestris pv. vesicatoria as an interactor of the plant cell death executor CaHIR1. The $\mathrm{Y} 2 \mathrm{H}$ and coimmunoprecipitation experiments revealed that Fha1 specifically interacts with CaHIR1 in vitro and in planta. Functional studies using mutant strains carrying the disrupted allele of the fhal open reading frame (ORF) (X. campestris pv. vesicatoria $\Delta$ fhal) revealed that Fha1 acts as a virulence factor during the colonization of the pathogen in plant tissues. Unexpectedly, the $\Delta$ fhal mutant strain showed increased adherence to plastic and plant leaf surfaces. Agrobacterium-mediated transient expression of fhal and infiltration of purified Fhal significantly induced a cell death response, and increased callose deposition and the accumulation of defense-related fluorescent compounds in pepper leaves. Loss-of-function analysis of the $\Delta$ fhal mutant in tomato and pepper plants showed that fhal functions as a virulence factor of $X$. campestris pv. vesicatoria during the compatible interaction with host plants. Taken together, the results of our study indicate that Fha1 of $X$. campestris pv. vesicatoria is recognized by membrane-resident CaHIR1 and is required for disease-associated cell death and defense responses in plants.

\section{RESULTS}

\section{CaHIR1 physically interacts}

with Fha1 in yeast and in planta.

We previously identified CaHIRl as a positive regulator of cell death associated with disease susceptibility and plant immunity (Choi et al. 2011; Jung and Hwang 2007). The CaHIRl gene encodes a stomatins, prohibitins, flotillins, and HflK/C domain-containing protein that localizes to the PM in a punctate pattern (Choi et al. 2011). Recently, Qi and associates (2011) showed that Arabidopsis HIR proteins are enriched in membrane microdomains in association with RPS2. Therefore, we hypothesized that CaHIR1 proteins may function as platforms for compartmentalization of cellular processes such as membrane transport, protein sorting, and signal transduction during pathogen infection (Browman et al. 2007; Qi and Katagiri 2012). To identify pathogen-derived proteins directly interacting with CaHIR1 and modulating its function, we screened a $X$. campestris pv. vesicatoria GAL4 $\mathrm{Y} 2 \mathrm{H}$ prey library using CaHIR 1 as bait. From approximately $5 \times 10^{6}$ clones, we initially identified part of the $X$. campestris pv. vesicatoria filamentous hemagglutinin-like protein 1 (fhal) gene as one of several putative interactors. To detect the full-length fhal, an X. campestris pv. vesicatoria genomic DNA library was constructed using the SuperCos 1 cosmid vector kit (Stratagene, La Jolla, CA, U.S.A.), followed by polymerase chain reaction (PCR)-based screening using the primers listed in Supplementary Table S1. The expected size of approximately $180 \mathrm{bp}$ of the fhal fragment was specifically amplified and sequenced from Cosmid 738 carrying an insert of approximately $40 \mathrm{~kb}$. Sequencing analyses of Cosmid 738 identified the full-length sequence of fhal (Supplementary Fig. S1). In a targeted Y2H assay, CaHIR1 physically interacted with the full-length Fha1 in yeast (Fig. 1A). A reciprocal interaction experiment confirmed the interaction between CaHIR1 and Fha1. The interaction between CaHIR1 and Fha1 was quantified by measuring the activity of liquid $\beta$-galactosidase using $o-N P G$ as a substrate (Supplementary Fig. S2). CaHIR1 and Fha1 did not auto-activate reporter gene expression when fused to the GAL4 activation domain (AD). However, the interaction of CaHIR1 with the full-length Fha1 significantly induced $\beta$-galactosidase activity.

To determine the specific interaction between CaHIR 1 and Fha1, we performed coimmunoprecipitation experiments (Fig. 1B). The His-tagged recombinant Fha1 was expressed and purified in Escherichia coli. Total proteins were then extracted from pepper leaves expressing cMyc-tagged CaHIR1 or empty vector. Protein extracts from pepper leaf tissues were incubated with or without His-tagged Fha1, and subjected to immunoprecipitation with an anti-cMyc antibody. After washing, the eluted protein complex was subjected to immunoblot anal- 
ysis using the anti-His antibody. The recombinant Fha1 was able to bind specifically to the plant-expressed CaHIR1 (Fig. 1B).

\section{Interaction and nuclear and cytoplasmic localization of Fha1 and CaHIR1.}

In our previous bimolecular fluorescence complementation (BiFC) experiments, CaHIR1 showed a punctate localization in the PM in association with CaLRR1 (Choi et al. 2011; Walter et al. 2004). Similarly, Arabidopsis HIR1 showed a punctate distribution pattern in the PM (Qi et al. 2011). To examine the heterodimerization of CaHIR1 with Fha1, a BiFC experiment was performed (Fig. 1C) by fusing the signal peptide sequence from $\mathrm{CaPO}$, which encodes extracellular peroxidase (Choi et al. 2007), to the N-terminal region of the Fhal protein to translocate plant-expressed Fha1 into the extracellular matrix. More recently, we reported that extracellular CaLRR1 interacts with CaHIR1 localized in the punctate site of the PM and the peripheral region of pepper epidermal cells (Choi et al. 2011). Yellow fluorescence protein (YFP) signals induced by heterodimerization of Fha1 with CaHIR1 were rarely detected in the PM; however, the YFP signal was mainly detected in endocytotic vesicle-like structures of heterogeneous sizes, also known as endosomes (Kang et al. 2010). A fraction of heterodimerizationinduced fluorescent signals also co-localized with 4',6-diamdino-2-phenylindole (DAPI)-stained nuclei (Supplementary Fig. S3). However, the YFP signal was not detected in the epidermal cells of Nicotiana benthamiana leaves infiltrated with single plasmids or empty vectors (data not shown). To more precisely determine subcellular localization of CaHIR1-Fha1 interactions, the endocytic tracer dye FM4-64 (Bolte et al. 2004) was infiltrated into $N$. benthamiana leaves (Fig. 1C). FM4-64 is rapidly incorporated in PM and diffuses laterally into contiguous membranes. The dye moves into internal cellular membranes only through an active endocytotic process, finally reaching vacuolar membranes (Bolte et al. 2004; Kankanala et al. 2007). Most of the yellow fluorescence induced by the Fha1-CaHIR1 interaction was sequestered in the FM464 red fluorescence, indicating that the CaHIR1-Fha1 complex localizes in the endocytic vesicle-like structure (Fig. 1C). However, the YFP signals induced by the Fha1-CaHIR1 interactions was relatively large in size and immobile.

\section{The fhal gene encodes an Fha-like protein.}

Sequence analysis of fhal revealed that the gene contains an ORF encoding a putative 445 -amino-acid (aa) protein, with a calculated molecular mass of $45.7 \mathrm{kDa}$. BLAST analysis indicated that the deduced amino acid sequence of Fhal contains three conserved Fha motifs involved in bacterial cell aggregation (Gottig et al. 2009; Rojas et al. 2002) (Fig. 2A). The translated Fha1 amino acid sequence showed the highest sequence identity (93\%) to the FhaB from X. axonopodis pv. citri. However, Fha1 lacks the conserved two-partner secretion domain, a highly conserved N-proximal region essential for secretion (Gottig et al. 2009). Despite the lack of the two-partner secretion domain, computational analysis of the putative amino acid sequence predicted that Fha1 may be an outer membrane protein (PSORTb, 99.2\%). Fha1 (445 aa) is considerably smaller than FhaB of $X$. axonopodis pv. citri (4,753 aa). A phylogenetic tree of Fha1 and its close relatives illustrates its proximity to Fha proteins from diverse bacterial species (Fig. 2B). Fha1 from X. campestris pv. vesicatoria Bv5-4a falls into a clade that consists of the Fha-like proteins from diverse Xanthomonas spp.

\section{Expression of fhal in $X$. campestris pv. vesicatoria.}

RNA gel blot analysis was performed to examine the expression pattern of fhal in bacterial cells (Supplementary Fig. S4). $X$. campestris pv. vesicatoria Bv5-4a was cultured overnight in yeast-nutrient (YN) medium at $28^{\circ} \mathrm{C}$. Bacterial cells were isolated at 4-h intervals after the lag phase. Expression of fhal increased gradually in $X$. campestris pv. vesicatoria during the exponential phase, reaching maximum levels during the stationary phase.

\section{Altered cell attachment and swarming motility of $X$. campestris pv. vesicatoria $\Delta$ fha1.}

To analyze the biological function of fhal, deletion mutants were generated from $X$. campestris pv. vesicatoria wild-type (WT) strain Bv5-4a by site-directed mutagenesis (Fig. 3A).
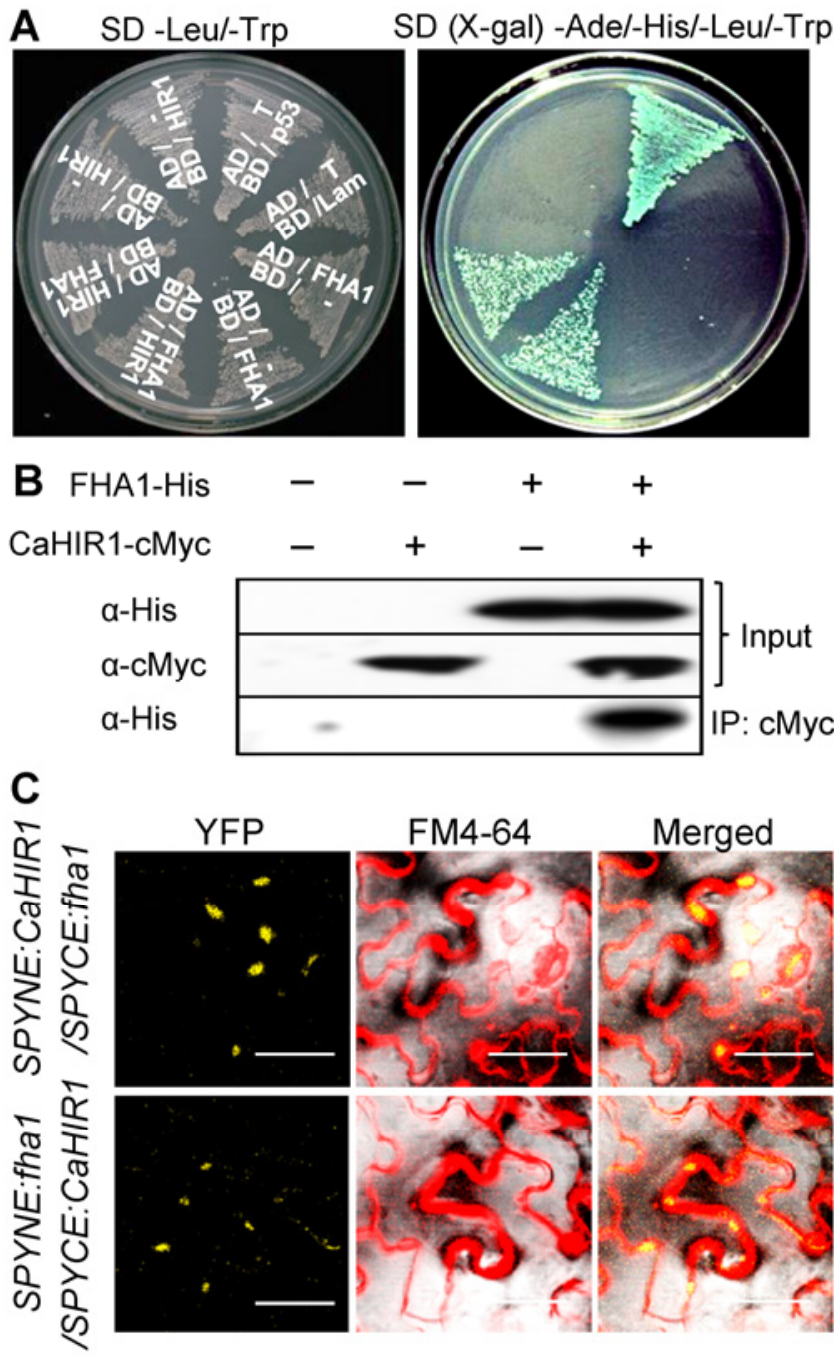

Fig. 1. Pepper CaHIR1 interacts with the Xanthomonas campestris pv vesicatoria filamentous hemagglutinin-like protein1 (Fha1) in yeast and in planta. A, Interaction of CaHIR1 with Fha1 in a GAL4-based yeast twohybrid system. Plasmids encoding the fusions to the GAL4 activation domain and the GAL4 DNA-binding domain are indicated by AD and $\mathrm{BD}$, respectively. Combinations of the Simian Vacuolating Virus 40 large $\mathrm{T}$ antigen $(\mathrm{AD} / \mathrm{T})$ with the murine p53 (BD/p53) fusion constructs and human lamic $\mathrm{C}(\mathrm{BD} / \mathrm{Lam})$ were included as positive and negative controls, respectively. B, Coimmunoprecipitation of CaHIR1 with Fha1. The $c M y c-$ tagged CaHIRl transgene was transiently expressed in pepper leaves by agroinfiltration. Total proteins extracted from the pepper leaves were incubated with or without His-tagged Fhal and subjected to immunoprecipitation with anti-cMyc antibody-conjugated beads. Total and immunoprecipitated proteins were hybridized with the indicated antibodies. C, Bimolecular fluorescence complementation visualization of the CaHIR1/Fha1 interaction in Nicotiana benthamiana leaves. Merged images include yellow fluorescence from yellow fluorescence protein (YFP) complementation by HIR1Fha1 interaction and red fluorescence from the endocytic tracer dye FM4-64. Bars $=50 \mu \mathrm{m}$. 
Analysis of fhal expression in $X$. campestris pv. vesicatoria and $\Delta \mathrm{f} h a l$ mutant strains by reverse-transcription (RT)-PCR (Fig. 3B) showed that full-length fhal transcripts (fhal) were not present in the deletion mutants. However, transcripts corresponding to the $\mathrm{N}$-terminal region of fhal $\left(f h a^{N}\right)$, which is located upstream of the insertion mutation, were more abundant in the $\Delta$ fhal mutant than in the WT X. campestris pv. vesicatoria strain. To complement the $\Delta$ fhal deletion mutant by site-directed mutagenesis, approximately $1 \mathrm{~kb}$ upstream of fhal was amplified by PCR, cloned into the pVIK112 vector,

A
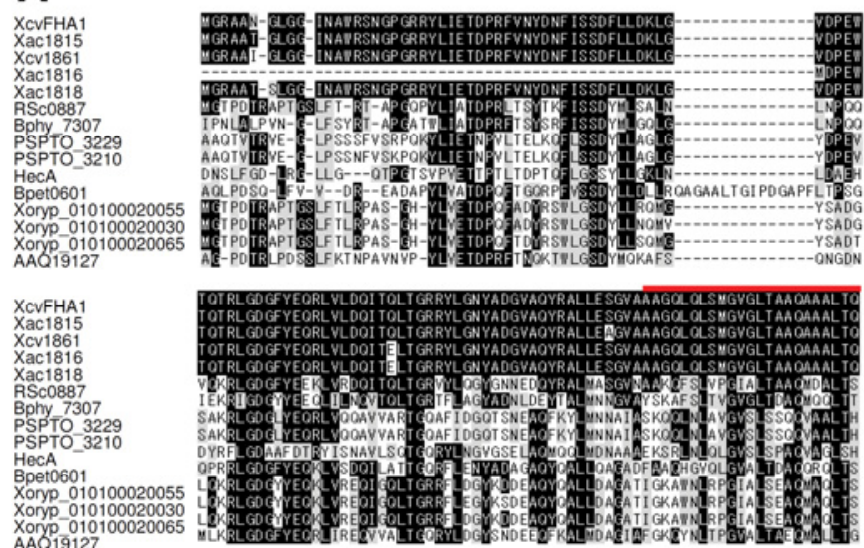

Xoryp 01010
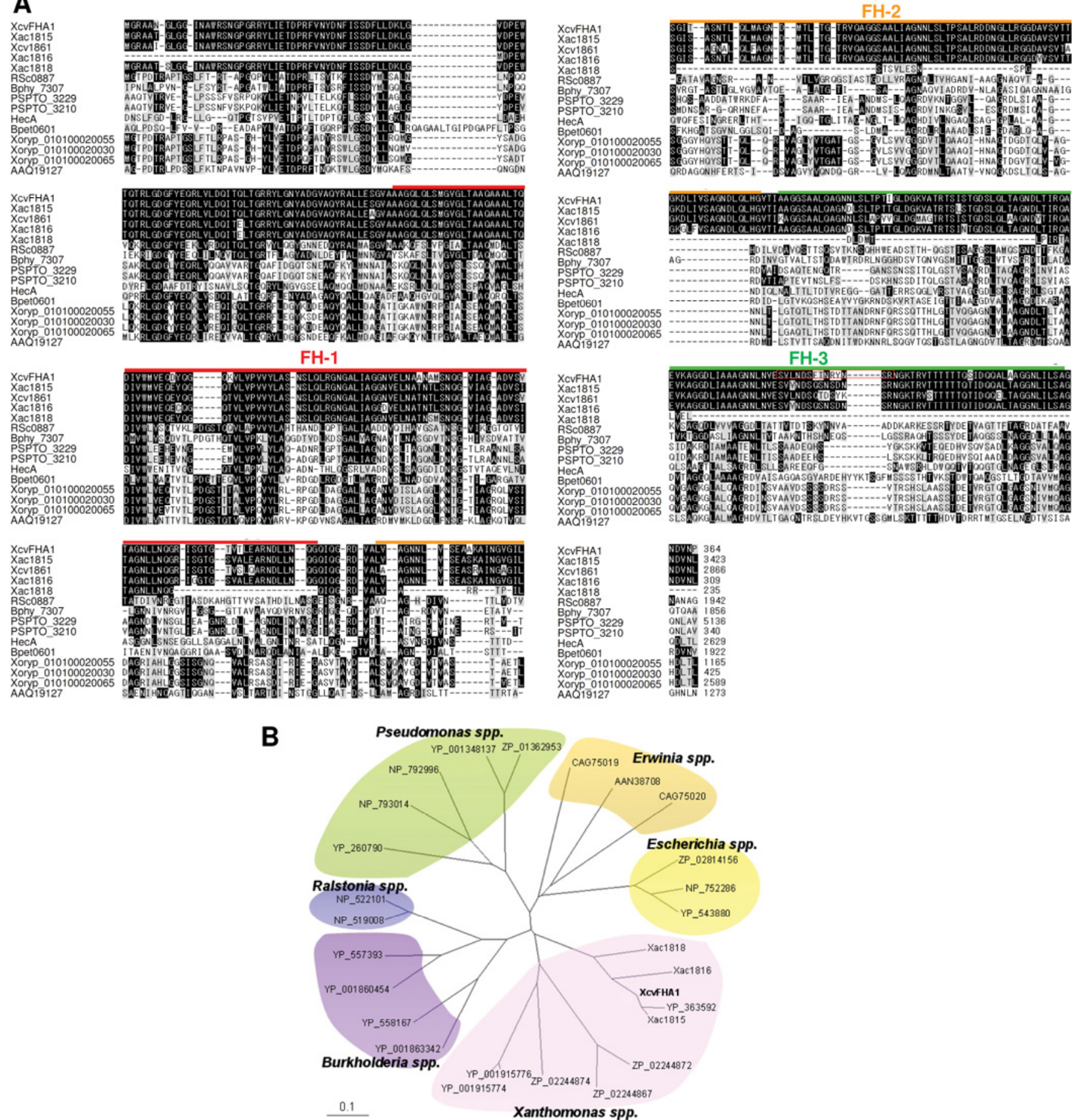

Fig. 2. Amino acid sequence alignment and phylogenic analysis of filamentous hemagglutinin-like protein1 (Fha1) with other Fha-like proteins. A, Amino acid sequence alignment of Fha1 with Fha-like proteins from Xanthomonas axonopodis pv. citri (Xac1815, accession number NP_642141; Xac1816, accession number NP_642142; Xac1818, accession number NP_642144), X. campestris pv. vesicatoria (Xcv1861, accession number YP_363592), Ralstonia solanacearum (RSc0887, accession number NP_519008), Burkholderia phymatum (Bphy_7307, accession number YP_001863342), Pseudomonas syringae (PSPTO_3229, accession number NP_793014; PSPTO_3210, accession number NP_792996), Erwinia chrysanthemi (HecA, accession number AAN38708), Bordetella petrii (Bpet0601, accession number YP_001629204), X. oryzae (Xoryp_010100020055, accession number ZP_02244872; Xoryp_010100020030, accession number ZP_02244867; Xoryp_010100020065, accession number ZP_02244874), and Escherichia coli (accession number AAQ19127). Three filamentous hemagglutinin domains (FH-1, FH-2, and FH-3) are indicated by lines over the sequences. C-proximal regions of Fha1 used for the generation of Fha1-specific peptide antibodies are indicated by a red box. B, An unrooted neighbor-joining dendrogram depicting the relationships among 27 representatives of Fha-like proteins. The scale value of 0.1 represents 0.1 amino acid substitutions per site. 
and used for bi-parental mating (Kalogeraki and Winans 1997). Complementation of fhal was confirmed by PCR amplification using chromosomal DNA of $X$. campestris pv. vesicatoria strains and by RT-PCR (Fig. 3B). Expression of fhal in the $\Delta$ fhal (fhal) strain was recovered to the WT X. campestris pv. vesicatoria level, indicating that the fhal ORF was fully complemented.

Fha proteins act as a major virulence factor to regulate bacterial adhesion and aggregation in plant and animal pathogens (Gottig et al. 2009; Kajava et al. 2001; Rojas et al. 2002). An in vitro adhesion assay using PVC microtiter well plates was performed to investigate whether the fhal mutation reduces bacterial adhesion. The $X$. campestris pv. vesicatoria, $\Delta$ fhal, and $\Delta$ fhal (fhal) strains grown in YN broth were washed tree times with phosphate-buffered saline (PBS) buffer (pH 7.0) and incubated in the wells for $6 \mathrm{~h}$. After washing off the planktonic bacterial cells, the remaining attached cells were stained with crystal violet (CV) (Fig. 4A). Solubilization of the CV stain in ethanol allowed an indirect, quantitative measurement of the adherent cell mass in a given well. Unexpectedly, the $\Delta$ fhal strain was more adherent to the surface of well plates than the WT $X$. campestris pv. vesicatoria and $\Delta$ fhal (fhal) strains, with threefold higher levels of CV stain retained. Consistent with this observation on the artificial plastic surface, $\Delta$ fhal also strongly adhered to the abaxial surface of tomato leaves compared with the WT and complemented strains (Fig. 4B), as shown by the high CV stain retention caused by $\Delta$ fhal adhesion. Next, the effect of the fhal mutation on bacterial

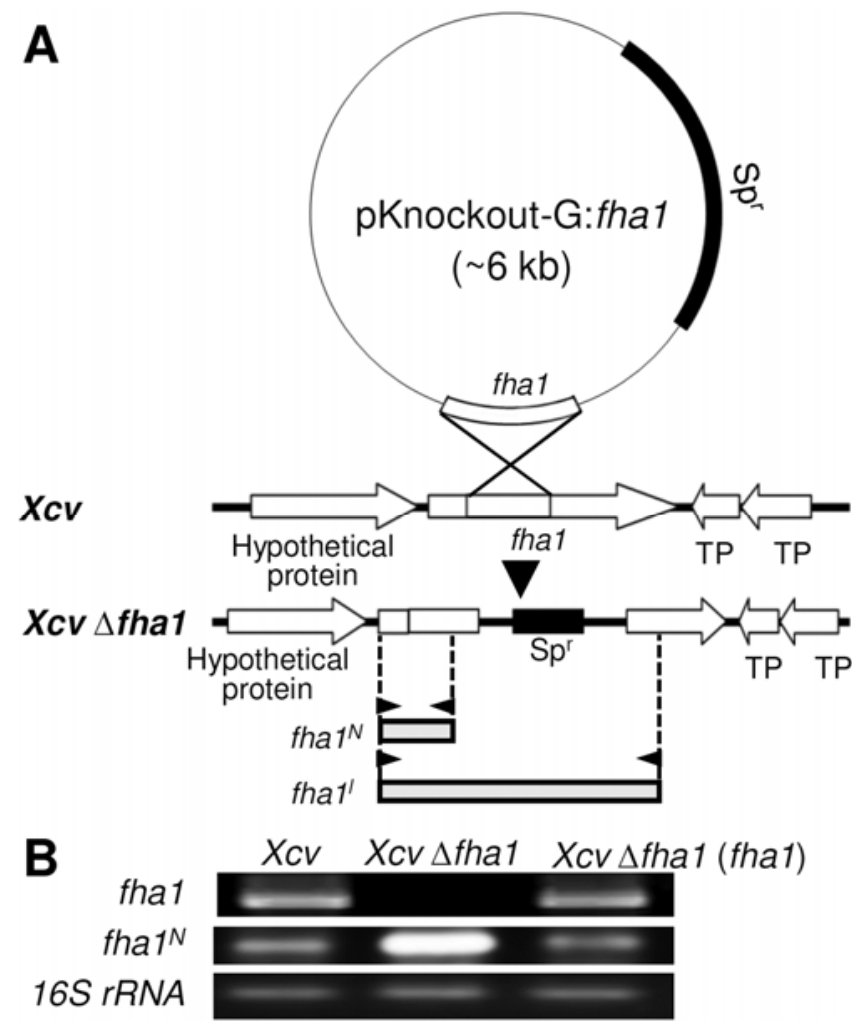

Fig. 3. Generation of Xanthomonas campestris pv. vesicatoria $\Delta$ fhal and $\Delta$ fhal (fhal) mutants from $X$. campestris pv. vesicatoria Bv5-4a. A, Schematic arrangement of the fhal genomic region and generation of the $\Delta$ fhal mutant. The approximately 6-kb pKnockout-G plasmid containing the fhal fragment was introduced into the wild-type Bv5-4a by triparental mating. Primer locations and amplified regions of fhal ${ }^{N}$ and fhal ${ }^{\text {Full }}$ in reverse-transcription polymerase chain reaction (RT-PCR) analyses are shown by black arrowheads and gray boxes, respectively. $\mathrm{Sp}^{r}=$ resistance to spectinomycin and TP $=$ transposase. B, RT-PCR analyses of the expression of fhal in $X$. campestris pv. vesicatoria, $\Delta$ fhal, and $\Delta$ fhal (fhal) strains. Different regions (fhal $1^{N}$ and $f h a 1^{F u l l}$ ) of the fhal gene were amplified. motility was examined by swarm plate analysis (Fig. 4C). The $\Delta$ fhal strain showed significantly lower swarming motility on the Silva Buddenhagen (SB) plate than the WT X. campestris pv. vesicatoria and complemented $\Delta$ fhal (fhal) strains (Gottig et al. 2009) (Fig. 4C). Measurement of motility zones after different incubation times showed that the $X$. campestris pv. vesicatoria and $\Delta$ fhal (fhal) strains moved faster than $\Delta$ fhal (Fig. 4C). Taken together, these results indicate that mutation of fhal enhanced the attachment of $X$. campestris pv. vesicatoria to various surfaces but reduced its swarming motility.

\section{Reduced virulence}

of $X$. campestris pv. vesicatoria $\Delta$ fhal in tomato plants.

To investigate the role of fhal in bacterial growth in host plants, the growth of the $X$. campestris pv. vesicatoria, $\Delta$ fhal,
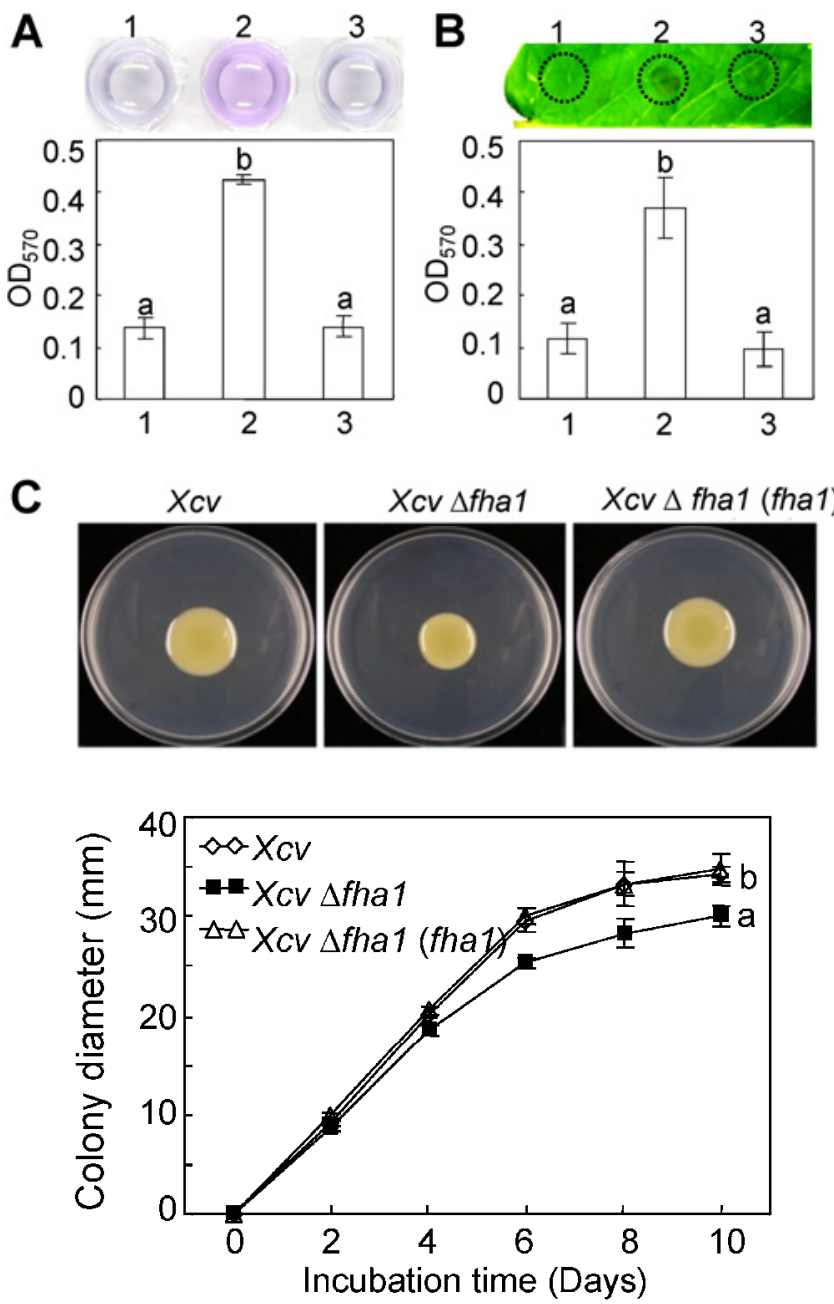

Fig. 4. Increased attachment and reduced swarming motility of the Xanthomonas campestris pv. vesicatoria $\Delta$ fhal mutant strain compared with $X$. campestris pv. vesicatoria and $\Delta$ fhal (fhal). A, Representative images and crystal violet $(\mathrm{CV})$ staining to visualize the adherence of bacteria to plastic (PVC) surfaces are shown. The adherence of bacteria to the plastic microwells was spectrophotometrically quantified after CV staining. Column 1 , wild-type $X$. campestris pv. vesicatoria; column $2, \Delta$ fha1; column 3 , $\Delta$ fhal (fhal). B, Representative images and CV staining to visualize the adherence of bacteria to 20 stained spots on the surface of tomato leaves are shown. The adherence of bacteria to the abaxial surface of tomato leaves was spectrophotometrically quantified after CV staining. Column 1, wild-

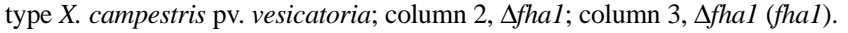
$\mathbf{C}$, Representative images and diameters of the motility zones of swarming bacteria on Silva Buddenhagen plates fortified with $0.7 \%$ agar. Data are the means \pm standard deviations from four independent experiments. Different letters indicate significant differences as determined by Fisher's least significant difference test $(P<0.05)$. 
A

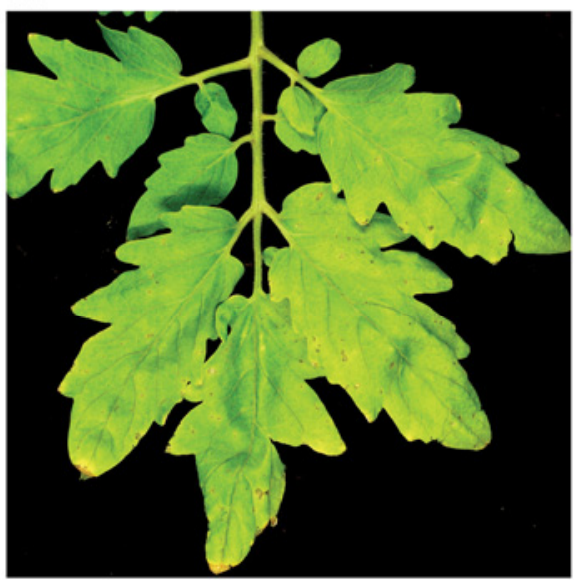

B

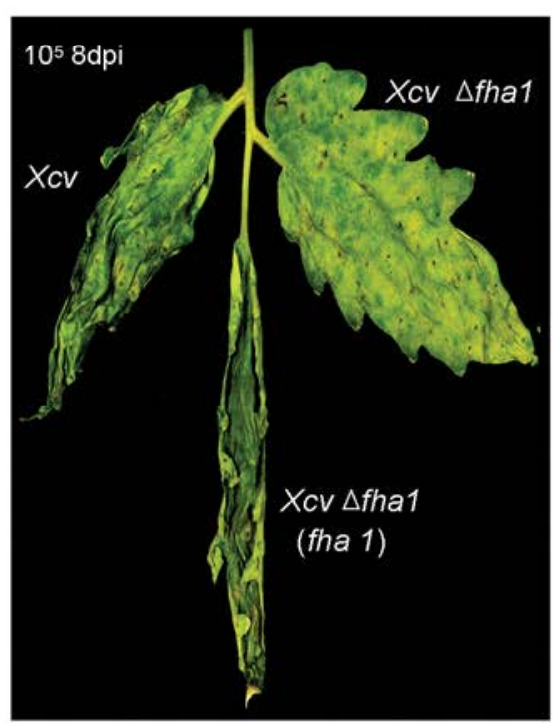

D

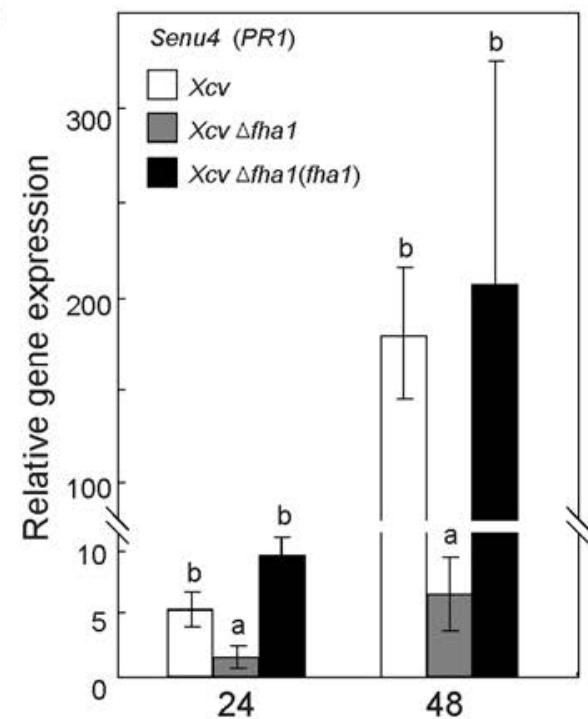

C
Xcv $\Delta$ fha1
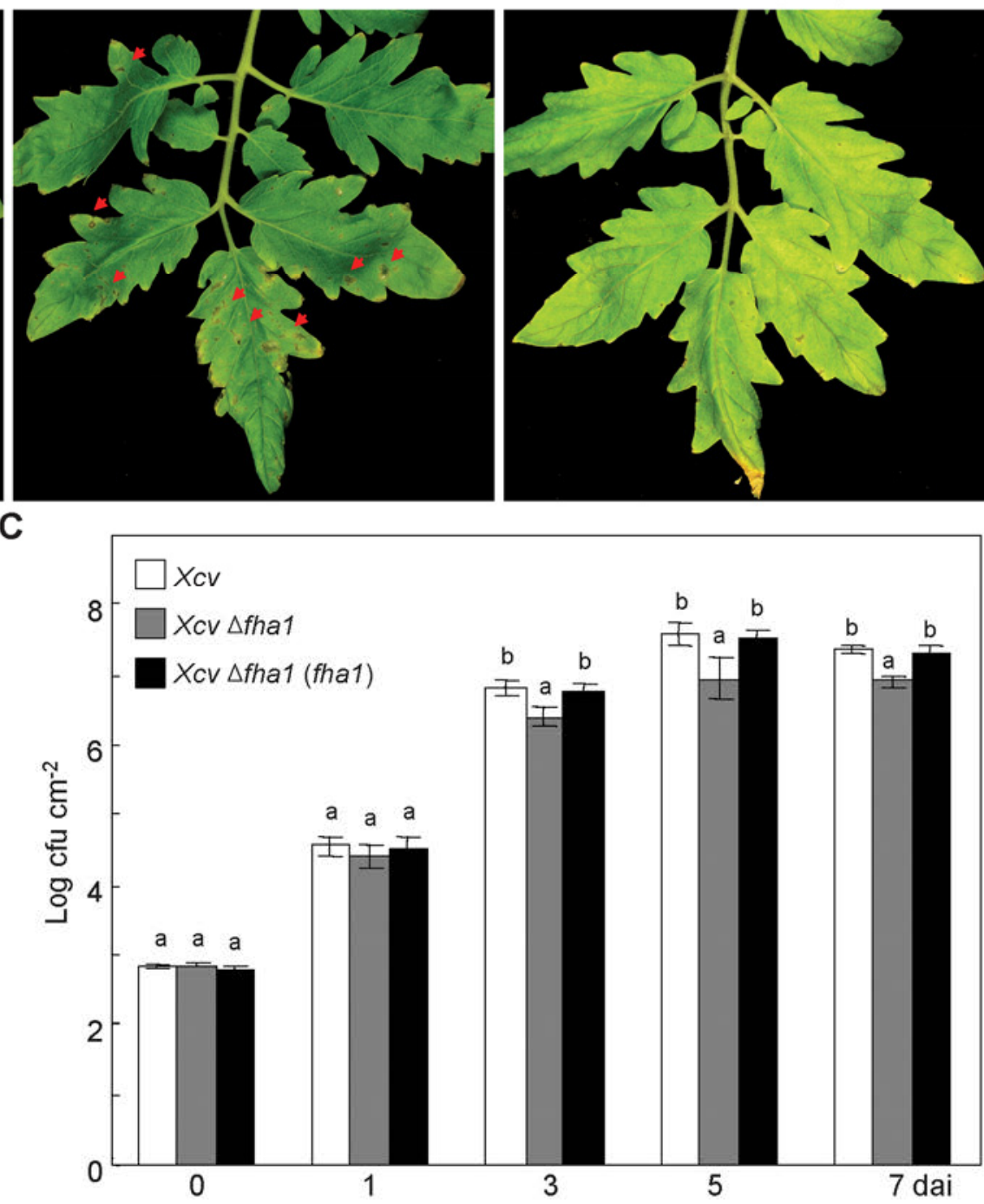

Xcv $\Delta$ fha1 (fha1)

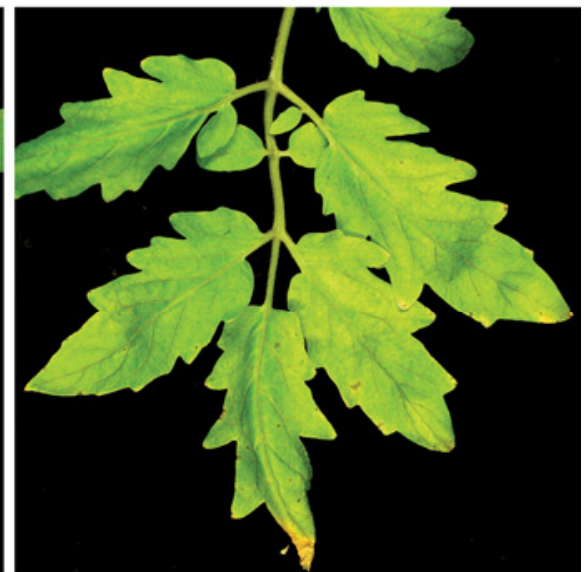

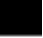
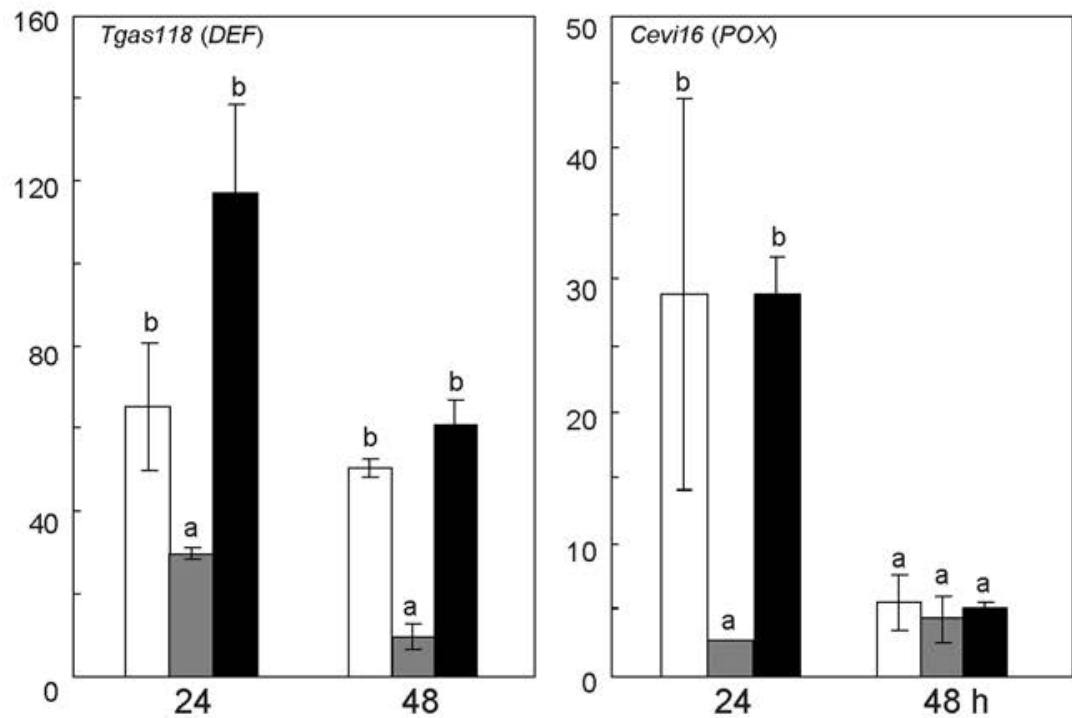

Fig. 5. Reduced virulence of the Xanthomonas campestris pv. vesicatoria $\Delta$ fhal mutant strain compared with X. campestris pv. vesicatoria and $\Delta$ fhal (fhal) in tomato leaves. A, Disease symptoms in tomato leaves 5 days after spray inoculation with $X$. campestris pv. vesicatoria, $\Delta$ fhal, and $\Delta$ fhal (fhal) $\left(10^{6} \mathrm{CFU}\right.$ $\mathrm{ml}^{-1}$ ). Localized necrotic lesions induced by $\Delta f h a 1$ are indicated by red arrowheads. B, Reduced disease symptoms of tomato leaves inoculated with $\Delta$ fhal. Images were acquired 8 days after syringe infiltration with $X$. campestris pv. vesicatoria strains $\left(10^{5} \mathrm{CFU} \mathrm{ml}^{-1}\right)$. C, Bacterial growth in tomato leaves $0,1,3$, 5 , and 7 days after inoculation with X. campestris pv. vesicatoria strains $\left(10^{5} \mathrm{CFU} \mathrm{ml}^{-1}\right)$. D, Quantitative real-time reverse-transcription polymerase chain reaction analysis of the expression of defense response genes in leaves infected with $X$. campestris pv. vesicatoria strains. Expression values are normalized to the expression of tomato ACTIN. $\mathbf{C}$ and $\mathbf{D}$, Data are the means \pm standard deviations from three independent experiments. Different letters indicate significant differences as determined by Fisher's least significant difference test $(P<0.05)$. 
and $\Delta$ fhal (fhal) strains was examined in tomato leaves at various time intervals after inoculation with $X$. campestris pv. vesicatoria (Fig. 5). The WT $X$. campestris pv. vesicatoria (strain Bv5-4a carrying avrBsT) used in this study elicited the hypersensitive response (HR) in pepper leaves, whereas it triggered a susceptible disease response in tomato leaves (Kim et al. 2010). Tomato leaves spray inoculated with the $\Delta$ fhal mutant showed localized necrotic spots but spreading chlorotic symptoms were not detected (Fig. 5A). By contrast, severe chlorotic disease symptoms developed on the total surface of tomato leaves 5 days after spray inoculation with $X$. campestris pv. vesicatoria and $\Delta$ fhal (fhal) strains $\left(10^{6} \mathrm{CFU}\right.$ $\left.\mathrm{ml}^{-1}\right)$.

Similar to the spray inoculation results (Fig. 5A), disease severity was lower in tomato leaves syringe infiltrated with $\Delta$ fhal than in those treated with $X$. campestris pv. vesicatoria and $\Delta$ fhal (fhal) (Fig. 5B). Growth of the $\Delta$ fhal mutant strain was significantly inhibited during infection compared with the growth of the $X$. campestris pv. vesicatoria and $\Delta$ fhal (fhal) strains (Fig. 5C). At 3 to 7 days after infiltration, the growth of $\Delta$ fhal showed a more than fivefold reduction compared with that of the $X$. campestris pv. vesicatoria strain in infected tomato leaves. As expected, the $\Delta$ fhal (fhal) strain exhibited a growth pattern similar to that of the X. campestris pv. vesicatoria strain in infected tomato leaves, suggesting that the reduced virulence of $\Delta f h a l$ is caused by the deletion of fhal.

We next investigated whether the fhal mutation affects the expression of pathogenesis-related $(P R)$ genes in tomato leaves (Fig. 5D). The $P R$ genes, including Senu4 (PRI) (Cunnac et al. 2007), Tgas118 (defensin) (van den Heuvel et al. 2001), and
Cevil6 (peroxidase) (Gadea et al. 1996), were significantly downregulated in tomato leaves infected with $\Delta$ fhal compared with $X$. campestris pv. vesicatoria and $\Delta$ fhal (fhal) infections. These data indicate that fhal functions as a positive regulator of $P R$ gene expression in tomato plants during $X$. campestris pv. vesicatoria infection.

\section{Reduced virulence of $X$. campestris pv. vesicatoria $\Delta a v r B s T / \Delta f h a 1$ in pepper plants.}

We investigated whether the fhal mutation affects the AvrBsT-triggered HR in pepper leaves infected with $X$. campestris pv. vesicatoria Bv5-4a (Fig. 6A and B). Inoculation with $\Delta$ fhal or $\Delta$ fhal (fhal) induced a similar HR as X. campestris pv. vesicatoria infection on pepper leaves (Fig. 6A). Bacterial growth in pepper leaves during infection for 7 days was not significantly different between $\Delta$ fhal and $X$. campestris pv. vesicatoria and $\Delta$ fhal (fhal) (Fig. 6B). These findings indicate that fhal expression may not inhibit the ETI in pepper.

Recently, we reported that mutation of $a v r B s T$ rendered the avirulent $X$. campestris pv. vesicatoria Bv5-4a virulent in pepper plants (Kim et al. 2010). Therefore, we generated the $X$. campestris pv. vesicatoria $\Delta a v r B s T / \Delta$ fhal mutant in the background of $X$. campestris pv. vesicatoria $\triangle a v r B s T$. As previously reported, $\triangle a v r B s T$ showed a higher level of virulence in pepper plants than $\Delta a v r B s T / \Delta f h a l 7$ and 14 days after inoculation (Fig. 6C). $\triangle a v r B s T$ infection induced severe disease symptoms in pepper leaves. Growth of the $\Delta a v r B s T / \Delta f h a l$ mutant in pepper leaves was significantly lower than that of $\triangle a v r B s T$ (Fig. 6D). These results indicate that fhal functions as a virulence factor of $X$. campestris pv. vesicatoria during the compatible interaction with host plants.

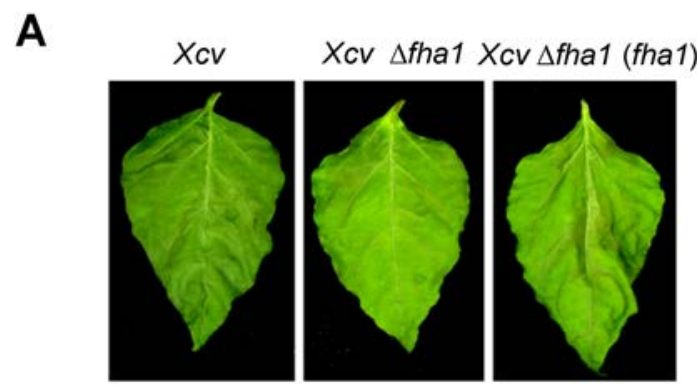

B

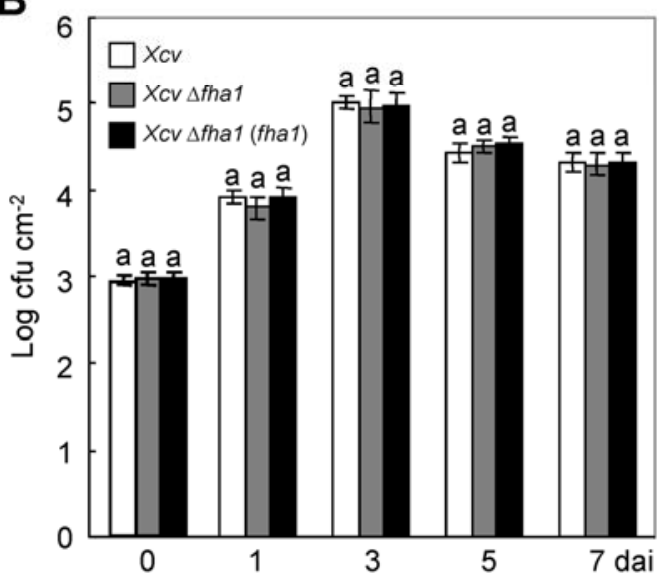

C

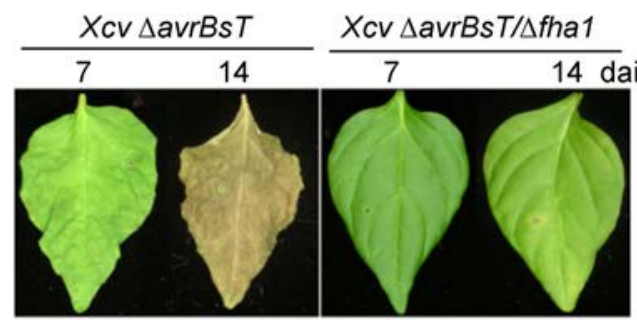

$D_{7}$

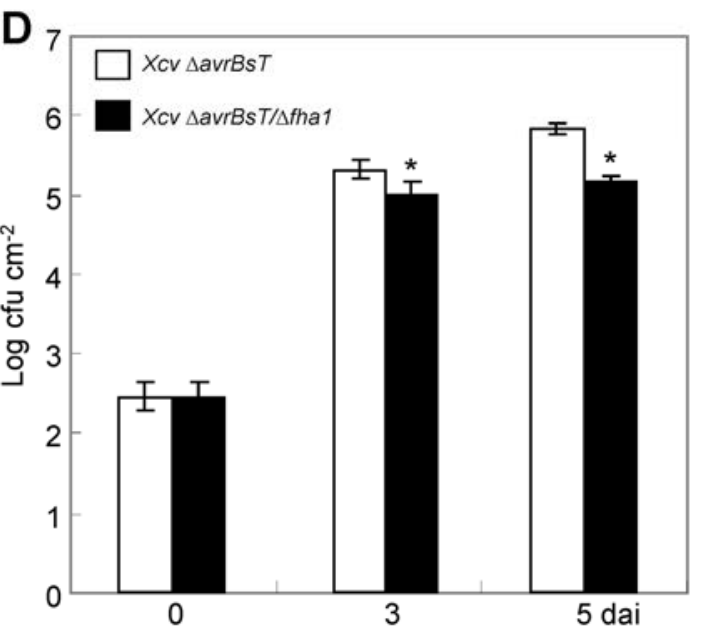

Fig. 6. Reduced virulence of Xanthomonas campestris pv. vesicatoria $\Delta a v r B s T / \Delta$ fhal compared with $\Delta$ fhal (fhal) in pepper leaves. A, Hypersensitive responses in pepper leaves 1 day after inoculation with $X$. campestris pv. vesicatoria, $\Delta$ fhal, and $\Delta$ fhal (fhal) $\left(10^{8} \mathrm{CFU} \mathrm{ml}^{-1}\right)$. B, Bacterial growth in

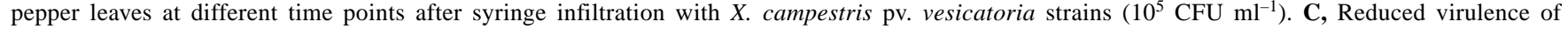
$\Delta a v r B s T / \Delta f h a l$ compared with $\triangle a v r B s T$. Images were acquired 7 and 14 days after syringe infiltration of pepper leaves with $X$. campestris pv. vesicatoria $\left(10^{5} \mathrm{CFU} \mathrm{ml^{-1 }}\right)$. D, Bacterial growth in pepper leaves at different time points after syringe infiltration with $X$. campestris pv. vesicatoria $\left(10^{5} \mathrm{CFU}\right.$ $\left.\mathrm{ml}^{-1}\right)$. B and $\mathbf{D}$, Data are the means \pm standard deviations from three independent experiments. Different letters indicate significant differences as determined by Fisher's least significant difference test $(P<0.05)$. Asterisks indicate significant differences between $\Delta a v r B s T$ and $\Delta a v r B s T / \Delta f h a l$ (Student's $t$ test, $P<0.05)$. 
Induction of the cell death response in pepper leaves by Fha1.

To investigate the in planta function of Fha1, we expressed fhal in pepper leaves by agroinfiltration. Transient overexpression of fhal resulted in cell death around the infiltration sites of pepper leaves (Fig. 7A). By contrast, leaves infiltrated with Agrobacterium carrying the empty-vector control (35S:00) did not show cell death symptoms. UV illumination of pepper leaves revealed the accumulation of cell-death-related fluorescent pigments in and around fhal-expressing regions 3 and 5 days after agroinfiltration. Only mild chlorotic symptoms were observed in empty-vector-expressing pepper leaves under UV light. The induction of cell death was supported by transient expression of fhal, which led to significantly enhanced callose deposition in pepper leaves 3 days after agroinfiltration, indicating that expression of fhal triggers cell death responses in pepper leaves (Fig. 7B).

\section{Co-expression of CaHIR1 with Fha1 enhances}

$X$. campestris pv. vesicatoria growth and disease susceptibility in pepper leaves.

The interaction of Fha1 with CaHIR1 in planta prompted us to investigate whether $C a H I R l$ expression is required for virulence and cell-death-inducing activities of fhal. $\triangle a v r B s T$ and $\Delta a v r B s T / \Delta f h a l$ strains were used to infect empty-vector control (Tobacco rattle virus [TRV]:00) and CaHIRl-silenced (TRV:CaHIRl) pepper plants. RT-PCR analysis revealed that CaHIRl expression was significantly reduced relative to emptyvector control plants (Fig. 8A). This indicates that CaHIRI was effectively silenced in pepper plants. CaHIRl silencing significantly compromised $\triangle a v r B s T$ growth in pepper leaves 3 and 5 days after inoculation (Fig. 8B). However, during $\triangle a v r B s T /$
A

XcV $\triangle$ avrBsT

Xcv $\Delta$ avrBsT/ $\triangle$ fha1 TRV:00 TRV:CaHIR1 TRV:00 TRV:CaHIR1

CaHIR1

$18 \mathrm{~S}$ rRNA
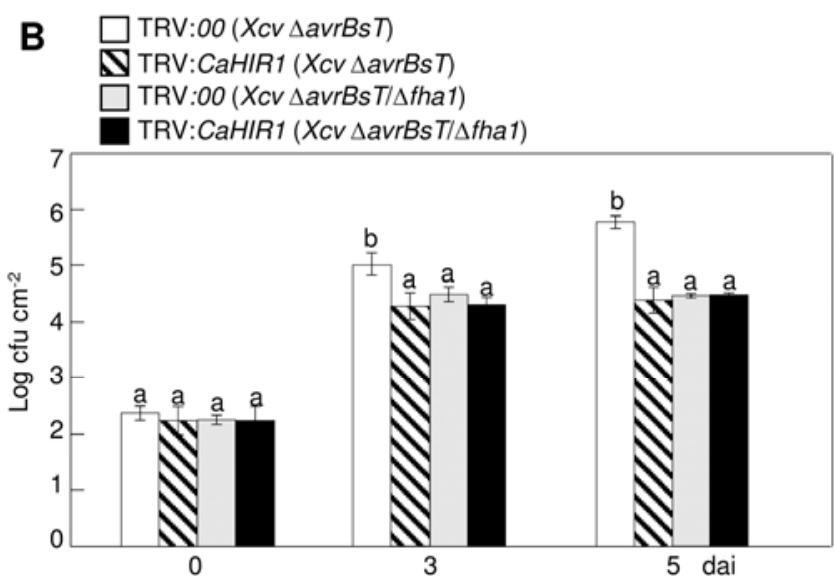

Fig. 8. A, Reverse-transcription polymerase chain reaction analysis of CaHIRI expression in empty-vector control (TRV:00) and CaHIRI-silenced (TRV:CaHIRI) pepper leaves $20 \mathrm{~h}$ after inoculation with Xanthomonas campestris pv. vesicatoria $\triangle a v r B s T$ and $\triangle a v r B s T \Delta$ fhal strains $\left(5 \times 10^{5}\right.$ CFU ml $\left.{ }^{-1}\right)$. B, Bacterial growth in empty-vector control and CaHIRIsilenced pepper leaves 0,3 , and 5 days after inoculation (dai) with $\triangle a v r B s T$ and $\triangle a v r B s T \Delta$ fhal strains $\left(5 \times 10^{5} \mathrm{CFU} \mathrm{ml}^{-1}\right)$. Data are the means \pm standard deviations from four independent experiments. Different letters indicate significant differences as determined by Fisher's least significant difference test $(P<0.05)$.

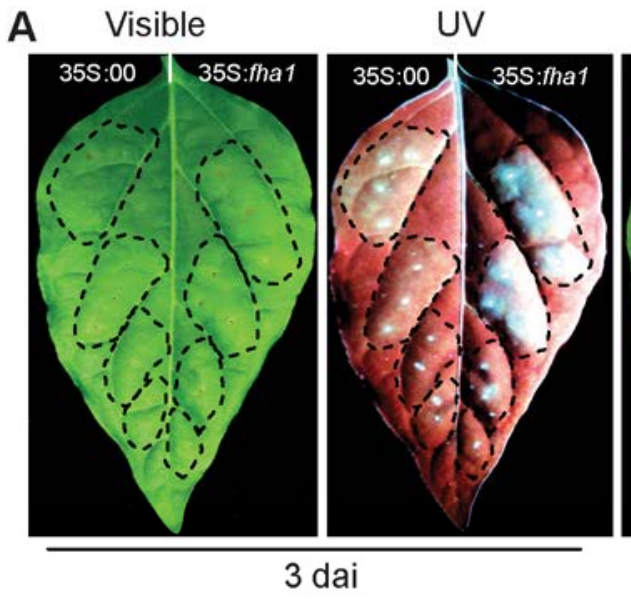

B

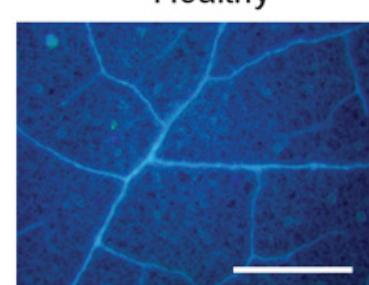

$(0.0 \pm 0.0)^{\mathrm{a}}$
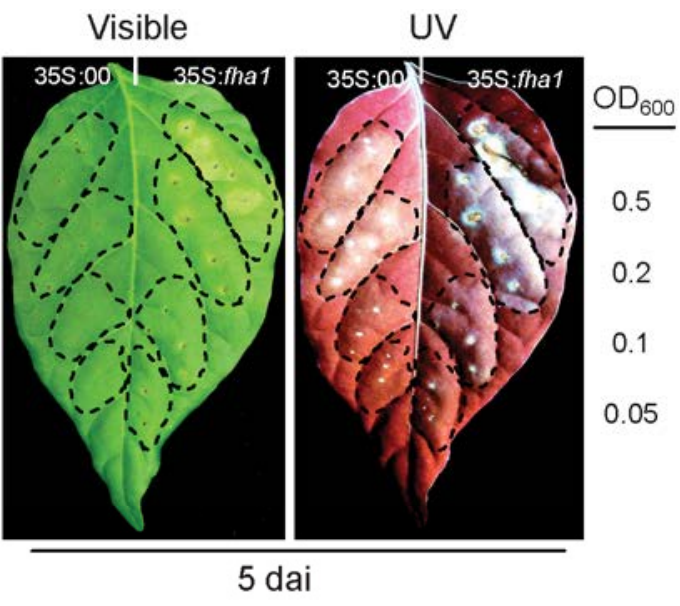

5 dai

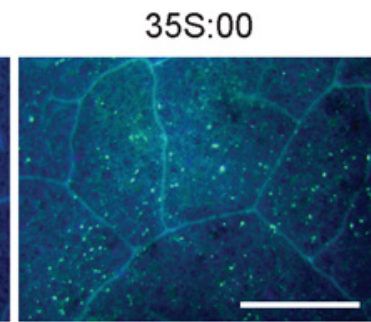

$(132 \pm 49.9)^{b}$
35S:fha1

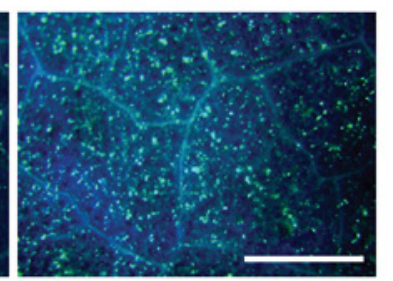

$(1018 \pm 198.1)^{\mathrm{c}}$

Fig. 7. Induction of cell death responses in pepper leaves by Agrobacterium-mediated transient expression of fhal. A, Accumulation of cell death-related fluorescent pigments in pepper leaves infiltrated with Agrobacterium tumefaciens carrying the empty vector pBIN35S (35S:00) or the pBIN35S:fhal construct (35S:fhal). Visible = a visible symptom on pepper leaves 3 and 5 days after agroinfiltration and UV = UV-exposure of pepper leaves to visualize the deposition of fluorescent pigments and chlorosis. B, Aniline blue staining of pepper leaves 3 days after infiltration with A. tumefaciens carrying the empty vector pBIN35S (35S:00) or the pBIN35S:fhal construct (35S:fhal). Agroexpression of fhal enhanced callose deposition in pepper leaves. Average numbers of callose foci are shown at the bottom. Data are the means \pm standard deviations from four independent experiments. Different letters indicate significant differences as determined by Fisher's least significant difference test $(P<0.05)$. 
$\Delta$ fhal infection, $C a H I R l$ silencing did not significantly reduce bacterial growth in CaHIRI-silenced plants, similar to that in the empty-vector control plants. Together, these results indicate that co-expression of CaHIR1 with Fha1 enhances $X$. campestris pv. vesicatoria growth and also disease susceptibility in pepper leaves.

CaHIR1 expression enhances induction of diseaseassociated cell death response by Fha1 application.

We next overexpressed and purified His-tagged Fha1 proteins in E. coli (Fig. 9A, left panel). Fha1 proteins were specifically detected by rabbit antibodies raised against the Fha1-specific peptide TAGKWPGDPDNKG (Fig. 9A, right panel). The purified recombinant Fhal protein was infiltrated into pepper leaves, and the activation of cell death and callose deposition were monitored by trypan blue and aniline blue staining (Supplementary Fig. S5A). Mock-infiltrated leaves did not show cell death induction or callose deposition. However, infiltration with $0.2 \mu \mathrm{M}$ Fha1 significantly increased callose deposition but not cell death induction in pepper leaves. Notably, increasing the concentration of Fha1 $(2 \mu \mathrm{M})$ significantly induced callose deposition as well as cell death. To determine whether the CaHIR1 is required for Fha1 to induce callose deposition and cell death, empty-vector- or CaHIRl-silenced pepper leaves were infiltrated with $2 \mu \mathrm{M}$ Fhal (Fig. 9B and C). When analyzed by trypan blue and aniline blue staining, CaHIRl silencing significantly reduced cell death and callose deposition induced by Fha1 application in pepper leaves, respectively (Fig. $9 \mathrm{~B}$ and $\mathrm{C}$ ). Together, these results suggest that Fha1 application induces disease-associated cell death through the interac- tion with CaHIR1, thereby enhancing the virulence of $X$. campestris pv. vesicatoria.

Analysis of the transcript levels of $P R$ genes, including $C a P R I$ and $C a D E F 1$, in Fha1-infiltrated pepper leaves showed that $C a P R 1$ and $C a D E F 1$ expressions were significantly downregulated in pepper leaves $24 \mathrm{~h}$ after infiltration with different concentrations of Fha1. Higher concentrations of Fha1 had a greater impact on suppressing CaPRl expression. To determine whether CaHIR1 is required for downregulation of $C a P R 1$ and $C a D E F 1$ expression by Fha1, we infiltrated Fha1 into empty-vector- or CaHIRI-silenced pepper leaves and monitored $C a P R I$ and $C a D E F 1$ expression. Infiltration with $2 \mu \mathrm{M}$ Fha1 significantly induced a high level of CaHIRI expression, and reduced CaPRl and CaDEFl expression, in the emptyvector control (TRV:00) plants (Fig. 9D). Notably, CaHIRI silencing did not affect reduction of CaPRI and CaDEF1 expression by exogenous Fhal application. This suggests that Fha1 may downregulate $C a P R l$ and $C a D E F 1$ expression independently of CaHIR1 upregulation, leading to the enhanced disease-associated cell death.

\section{Enhanced cell death and altered disease susceptibility of fhal-overexpressing transgenic Arabidopsis.}

Because pepper plants are difficult to transform, we generated fhal-overexpressing (OX) transgenic Arabidopsis plants to examine the biological function of fhal in plants. Constitutive expression of the fhal transgene was detected in the fhalOX lines 2, 3, and 4 (Supplementary Fig. S6), which were selected for further experiments. The fhal-OX transgenic Arabidopsis plants exhibited retarded growth (Fig. 10A) and consti-
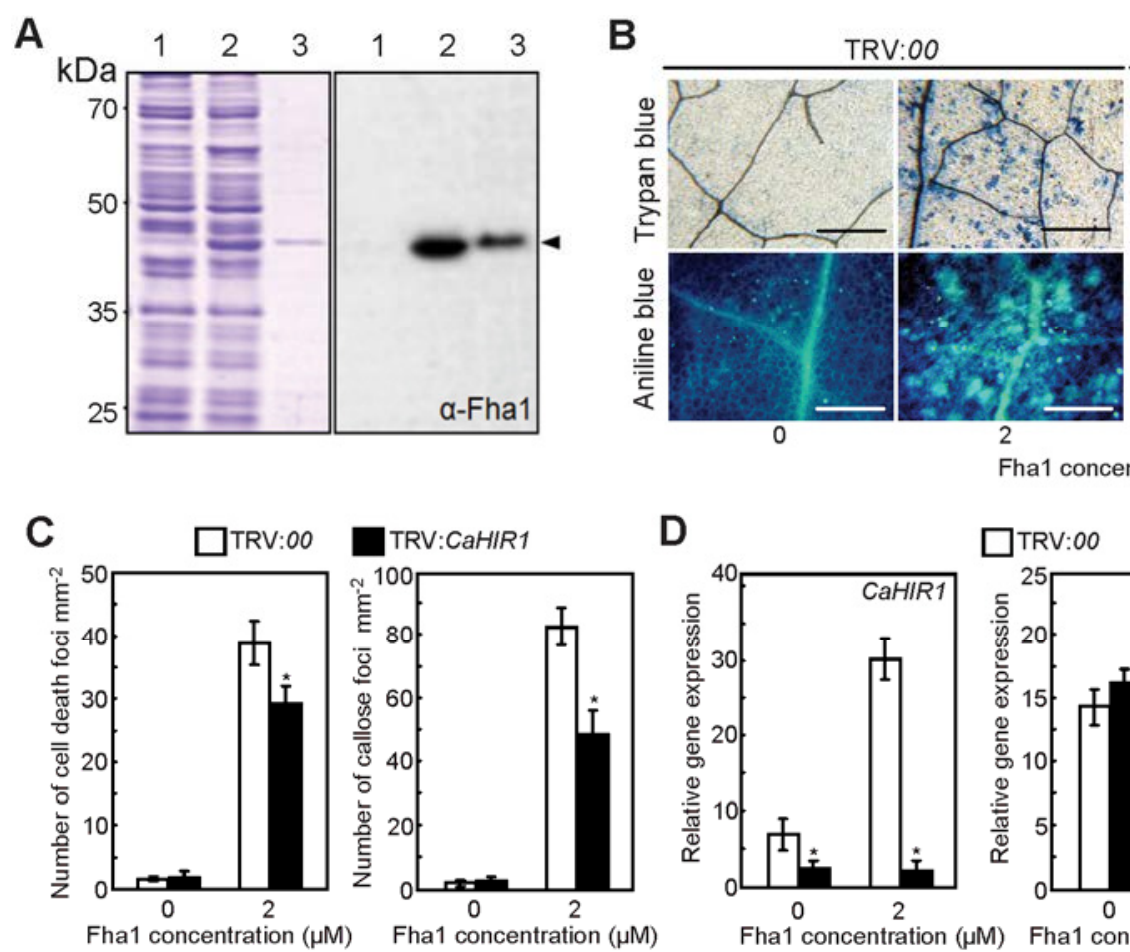

Fha1 concentration $(\mu \mathrm{M})$
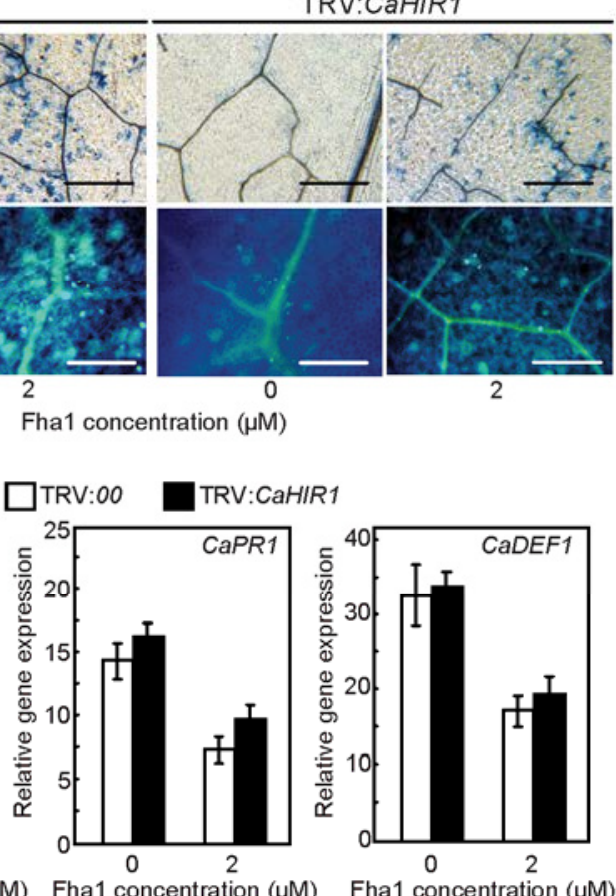

Fig. 9. Induction of susceptibility cell death response in the empty vector (TRV:00) and CaHIRl-silenced (TRV:CaHIRI) pepper leaves by infiltration with purified Fha1 protein. A, Purification and protein gel blot analyses of Fha1. Sodium dodecyl sulfate polyacrylamide gel electrophoresis of the purified Histagged Fha1 protein (left panel). Gel lanes are as follows: lane 1, soluble crude Escherichia coli/Fha1 extract, noninduced; lane 2, soluble crude E. coli/Fha1 extract, as induced with $1 \mathrm{mM}$ isopropyl- $\beta$-D-thio-galactoside; lane 3, recombinant His-Fha1 fusion protein purified on a Ni-NTA column. Protein gel blot analysis of His-tagged Fha1 protein using rabbit polyclonal antibodies against Fha1 (right panel). B, Trypan blue and aniline blue staining of pepper leaves 1 day after infiltration with purified Fha1 protein. Bars $=200 \mu \mathrm{m}$. C, Quantification of cell death and callose deposition in leaf tissues by trypan blue and aniline blue staining $24 \mathrm{~h}$ after infiltration with purified Fha1 protein, respectively. D, Quantitative reverse-transcription polymerase chain reaction analyses of the expression of CaHIRl, CaPRl (PR-1), and CaDEF1 (defensin) in pepper leaves 24 h after infiltration with Fha1 protein. Expression values are normalized to the expression of pepper $18 \mathrm{~S}$ rRNA. C and D, Data are the means \pm standard deviations from four independent experiments. Asterisks indicate significant differences between the empty-vector control (TRV:00) and CaHIRI-silenced (TRV:CaHIRI) plants (Student's $t$ test, $P<0.05$ ). 
tutive cell death phenotypes as observed by trypan blue staining (Fig. 10B). Cell death phenotypes were mainly observed in the marginal region of the transgenic Arabidopsis leaves. Infection with virulent Pseudomonas syringae pv. tomato DC3000 distinctly induced disease-associated cell death in the fhal-OX transgenic leaves compared with the WT plants (Fig. 10C). Consistent with the enhanced disease-associated cell death symptoms, fhal-OX transgenic plants showed significantly higher bacterial growth 3 days after inoculation than WT plants (Fig. 10D).

\section{DISCUSSION}

Pathogens have evolved various virulence factors that overcome plant surveillance systems by suppressing basal resistance. However, the host proteins targeted by pathogen virulence factors are largely unknown. Recognition of pathogen-derived general elicitors or PAMPs triggers the activation of a variety of downstream defense signaling pathways (Altenbach and Robatzek, 2007; Chinchilla et al. 2006; Kunze et al. 2004). Previously, the pepper PM-resident CaHIR1 protein was identified as a positive regulator of pathogen-induced cell death associated with plant immunity and disease but as a negative regulator of $P R$ gene expression (Choi et al. 2011; Jung and Hwang 2007; Jung et al. 2008). CaHIR1 accumulates in pepper leaves during the compatible and incompatible interactions of pepper plants with virulent strain Ds1 and avirulent strain Bv5-4a of X. campestris pv. vesicatoria, respectively; however, the accumulation of CaHIR1 is stronger and more prolonged in the incompatible interaction. Recently, we identified $X$. campestris pv. vesicatoria Bv5-4a harboring the effector protein AvrBsT, which is secreted into plant cells and induces HRlike cell death in pepper plants but suppresses basal defense in tomato plants (Kim et al. 2010). Furthermore, microdomain formation by direct interaction of HIR1 with its cellular partner LRR1 or RPS2 in pepper and Arabidopsis, respectively, implicates the role of HIR proteins in the perception of pathogen-derived signaling molecules and in the activation of downstream defense signaling (Choi et al. 2011; Qi et al. 2011). To better understand the CaHIR1-mediated defense signaling, we performed $\mathrm{Y} 2 \mathrm{H}$ screening and identified a small Fha-like protein of $X$. campestris pv. vesicatoria (Fha1) as an interactor of CaHIR1.

The surface-exposed Fha of gram-negative bacteria is known as one of the most important adhesin proteins, along with fimbriae (Locht et al. 2001). In addition to its importance for bacterial adherence, the Fha protein has been used as an antigen to immunize humans against whooping cough caused by $B$. pertussis (Goebel et al. 2009; Rieber et al. 2008). These findings suggest that Fha acts both as a virulence factor by facilitating bacterial adherence and as an immunogen perceived by the mammalian immune system. Similar to their activity in animal systems, bacterial Fha proteins may play an important role in the adherence of bacteria to plant surfaces and their aggregation in plant tissues (Gottig et al. 2009; Guilhabert and Kirkpatrick 2005; Rojas et al. 2002). However, their target or receptor proteins have not been identified in plants. In the present study, $\mathrm{Y} 2 \mathrm{H}$, coimmunoprecipitation, and $\mathrm{BiFC}$ experiments showed that Fha1 specifically interacts with CaHIR 1 in vitro and in planta. These findings suggest that CaHIR1 directly recognizes Fha1 during $X$. campestris pv. vesicatoria infection. Previously, we showed that PM-localized CaHIR1 binds to the extracellular CaLRR1 in yeast and in planta, suggesting the capability of CaHIR1 to interact with the extracellular proteins (Choi et al. 2011). Computational analysis of the subcellular localization using the PSORTb program predicted that Fha1 may be present in the bacterial outer membrane. Therefore, surface-exposed
Fha1 of $X$. campestris pv. vesicatoria may be able to interact with CaHIR1 during infection. However, lack of the conserved two-partner secretion domain in Fha1 raises the possibility that it could reside in the bacterial cytoplasm. Plants and animals have evolved recognition systems not only for microbial surface-exposed elicitors but also for cytoplasmic molecular structures that are essential for the architecture and function of microbial cells (Felix and Boller 2003; Zipfel and Felix 2005). However, it is largely unknown how and where plant or animal cells recognize such pathogen-derived hidden molecules, although lytic enzymes of the hosts and phagocytosis appear to play important roles in releasing these hidden or embedded molecules from microbes (Zipfel and Felix 2005). In any case, it would be interesting to test whether the CaLRR1 or CaHIR1 heterodimer has a high affinity with Fha1. In our previous BiFC analyses, most of the fluorescent signals induced by heterodimerization of CaLRR1 with CaHIR1 were located in the punctate site of the PM and the peripheral region of pepper epidermal cells (Choi et al. 2011). Interestingly, in our present study, YFP signals induced by heterodimerization of Fha1 with CaHIR1 were rarely detected in the PM. However, the co-localization of YFP signal with the endocytic tracer dye FM4-64 revealed that the Fha1-CaHIR1 complex is located in endocytic vesicle-like structures of heterogeneous sizes, known as endosomes (Kang et al. 2010). A fraction of heterodimerization-induced fluorescent signals also was found around the DAPI-stained nuclei. Notably, Arabidopsis PM-localized PRR FLS2 was reported to be internalized into the intracellular mobile vesicles within $30 \mathrm{~min}$ after stimulation with the flagellin epitope flg22, followed by its
A

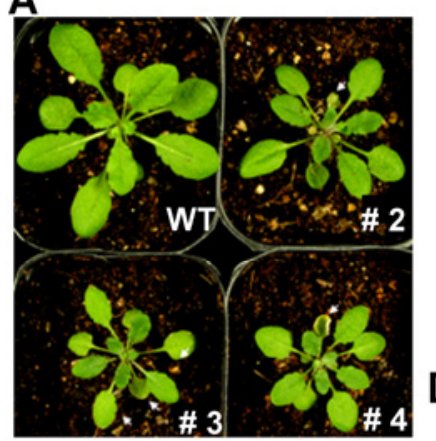

B

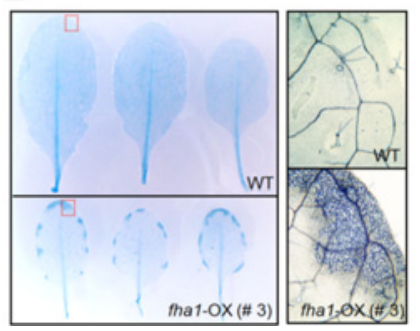

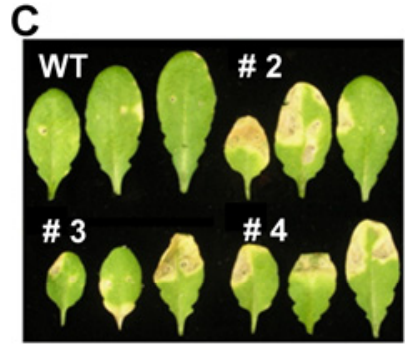

D

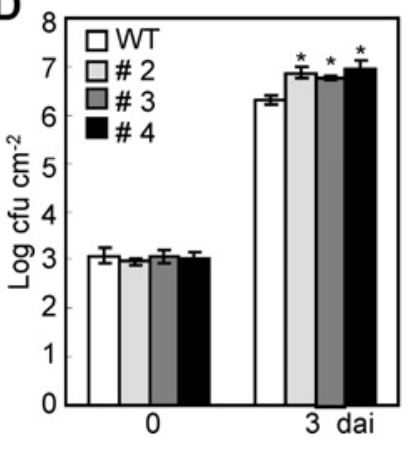

Fig. 10. Increased cell death and disease susceptibility of fhal-overexpressing (OX) transgenic Arabidopsis plants (numbers 2, 3, and 4) in response to Pseudomonas syringae pv. tomato DC3000 infection. A, Retarded growth of transgenic plants grown on soil for 4 weeks. Visible cell death phenotypes in the fhal-OX Arabidopsis leaves are indicated by white arrows. B, Trypan blue staining of pathogen-independent dead cells in fhal-OX Arabidopsis leaves. Insets (right panel) show an enlargement of the red-colored boxed areas (left panel). C, Leaves of fhal-OX Arabidopsis plants showed increased disease symptoms 8 days after inoculation with virulent DC3000. D, Increased bacterial growth in fhal-OX transgenic Arabidopsis. Bacterial growth was measured 0 and 3 days after inoculation with virulent DC3000 $\left(10^{5} \mathrm{CFU} \mathrm{ml}^{-1}\right)$. Data represent the means \pm standard deviations from three independent experiments. Asterisks indicate significant differences between wild-type (WT) and each of the fhalOX lines (Student's $t$ test, $P<0.05$ ). 
degradation (Robatzek et al. 2006). These findings raise the possibility that Fha1 may also be able to induce internalization of CaHIR1 after their recognition. In Arabidopsis, the PMlocalized PRR FLS2 and elongation factor Tu (EF-Tu) receptor directly bind flg22 and EF-Tu, respectively, and elicit PTI, which is accompanied by callose deposition and cell death (Chinchilla et al. 2006; Gao et al. 2009; Göhre et al. 2008; Zipfel 2008; Zipfel et al. 2006). Similar to the morphologically distinct phenotype in Arabidopsis, Agrobacterium-mediated transient expression of fhal and infiltration of purified Fhal also strongly induced susceptibility cell death, accumulation of defense-related fluorescent compounds, and callose deposition in pepper leaves. Similarly, transient expression of CaHIRI also induced strong callose deposition in pepper leaves (Choi et al. 2011). These findings strongly suggest that CaHIR1 directly recognizes the $X$. campestris pv. vesicatoria virulence factor Fha1 to activate CaHIR1-mediated susceptibility cell death responses in pepper plants, leading to the hypothesis that the recognition of Fha1 by CaHIR1 triggers disease-associated cell death response in pepper plants during $X$. campestris pv. vesicatoria infection. Interestingly, a small fraction of heterodimerization-induced fluorescent signals also was detected around the DAPI-stained nuclei. Further studies of subcellular localization of CaHIR1 and its interacting partner proteins, such as Fha1 and CaLRR1 (Choi et al. 2011) in pepper and RPS2 (Qi et al. 2011) in Arabidopsis, will be required to understand how plants specifically recognize pathogen-derived molecules or elicitors to activate downstream signals.

Previous studies showed that mutation of the $F$ haB allele reduces adherence of Erwinia chrysanthemi and $X$. axonopodis to plant surfaces, thus suppressing the virulence of the plant pathogens (Gottig et al. 2009; Guilhabert and Kirkpatrick 2005; Rojas et al. 2002). Therefore, we investigated whether Fha1 functions as a virulence factor by using a mutant $X$. campestris pv. vesicatoria strain carrying the disrupted allele of fhal ( $\Delta$ fhal) and its complemented strain $\Delta$ fhal (fhal). As expected, the basal resistance of tomato plants was significantly higher against $\Delta$ fhal infection than against $X$. campestris pv. vesicatoria or $\Delta$ fhal (fhal) infection. The expression of various $P R$ genes was also significantly lower in $\Delta f$ hal-inoculated tomato leaves than in those inoculated with $X$. campestris pv. vesicatoria or $\Delta$ fhal (fhal). These findings suggest that fhal expression is required for the full virulence of $X$. campestris pv. vesicatoria and mutation of fhal compromised the virulence of $X$. campestris pv. vesicatoria in the host tomato plants. However, in pepper plants, we did not detect a significant difference in the HR or bacterial growth between infection with $X$. campestris pv. vesicatoria or $\Delta$ fhal, suggesting that the ETI of pepper plants is strong enough to suppress the Fha1-induced susceptibility. More recently, avrBsT of X. campestris pv. vesicatoria has been identified as a key effector protein that positively regulates an incompatible interaction between $X$. campestris pv. vesicatoria and pepper plants (Kim et al. 2010). Therefore, we used the $\triangle a v r B s T$ mutant strain to investigate whether fhal functions as a virulence factor in pepper during infection by $X$. campestris pv. vesicatoria. As expected, $\Delta a v r B s T / \Delta$ fhal showed significantly reduced virulence in terms of reduced bacterial growth and disease severity in pepper leaves. Silencing of $C a H I R I$ conferred enhanced resistance of pepper plants to $\triangle a v r B s T$ infection. Consistent with our previous studies (Choi et al. 2011), these findings suggest that CaHIRl expression contributes to disease susceptibility in plants. More importantly, $\triangle a v r B s T$ did not show enhanced virulence in CaHIRl-silenced plants compared with $\Delta a v r B s T /$ $\Delta$ fhal, suggesting the requirement of CaHIR1 for Fha1 to activate $X$. campestris pv. vesicatoria virulence. Taken together, these results suggest that the interaction of Fha1 with CaHIR1 plays a pivotal role in $X$. campestris pv. vesicatoria virulence during the infection of host plants.

In vitro and in planta attachment assays revealed that the adherence of $\Delta f h a l$ to both plastic and plant leaf surfaces was significantly higher than that of the $X$. campestris pv. vesicatoria and $\Delta$ fhal (fhal) strains. On the other hand, the swarming motility of $\Delta$ fhal was significantly reduced in the SB agar plates. Furthermore, tomato leaves infected with $\Delta$ fhal showed localized necrotic lesions but failed to develop spreading chlorotic symptoms on the entire leaf surface. This suggests that fhal expression negatively regulates bacterial adherence but positively regulates $X$. campestris pv. vesicatoria motility. Infiltration of the recombinant Fhal protein into pepper leaves induced callose deposition and cell death but significantly lowered $P R$ gene expression compared with the mock-inoculated leaves. These findings suggest that the interaction of CaHIR1 with Fha1 not only induces susceptibility cell death but also actively suppresses $P R$ gene expression. Notably, dosage-dependent lowered $P R$ gene expression in pepper leaves infiltrated with recombinant Fha1 compared with mock-infiltrated leaves suggests its suppressive role in plant immunity but excludes the phytotoxic effect of Fha1. This was supported by previous results showing that CaHIR1 positively regulates $\mathrm{HR}$ and disease-associated cell death but negatively regulates plant defense-related hormone salicylic acid accumulation and $P R$ gene expression (Choi et al. 2011). Taking all available evidence together, we suggest that Fha1 enhances pathogen virulence by regulating $X$. campestris pv. vesicatoria motility, and suppresses plant basal defense by compromising $P R$ gene expression in association with CaHIR1 (Supplementary Fig. S7). Accumulation of Fha1 enhances bacterial motility, increasing the spread of bacteria in plant tissues. Plants also activate disease-associated cell death upon recognition of Fha1 by CaHIR1. Furthermore, Fha1-triggered cell death suppresses $P R$ gene expression to overcome the basal defense response in host plants.

\section{MATERIALS AND METHODS}

\section{Y2H screening.}

The MATCHMAKER GAL4 two-hybrid system (Clontech, Palo Alto, CA, U.S.A.) was used in this study. The genomic DNA library of $X$. campestris pv. vesicatoria Bv5-4a was constructed in the GAL4 AD vector (pGADT7). The bait construct was also prepared by cloning the coding region for CaHIRl into the GAL4 DNA-binding domain vector (pGBKT7). The $X$. campestris pv. vesicatoria prey library and the bait construct were co-transformed into yeast strain AH109 and the transformed yeasts were plated on minimal synthetic dropout media lacking histidine, leucine, and tryptophan. Positive samples were subsequently placed four times on media lacking adenine, histidine, leucine, and tryptophan with X-GAL to monitor the activation of the HIS3, ADE2, and MEL1 reporter genes. Reciprocal switch experiments using the isolated clones were performed to confirm their specific interaction.

\section{Overexpression and purification of Fha1.}

The ORF region of fhal was cloned into the pET22ba vector (Novagen, San Diego, CA, U.S.A.). Constructs for protein expression were transformed into Escherichia coli BL21 (Invitrogen, Carlsbad, CA, U.S.A.) and grown overnight in $5 \mathrm{ml}$ of Luria-Bertani (LB) medium at $37^{\circ} \mathrm{C}$. An aliquot of the culture was added to $50 \mathrm{ml}$ of $\mathrm{LB}$ broth and grown at $37^{\circ} \mathrm{C}$ to an optical density at $600 \mathrm{~nm}\left(\mathrm{OD}_{600}\right)=0.5$. Protein expression was induced with $1 \mathrm{mM}$ isopropyl- $\beta$-D-thio-galactoside for $12 \mathrm{~h}$ at $28^{\circ} \mathrm{C}$. Bacterial cells harvested by centrifugation were resuspended in $1 \times$ PBS buffer ( $\mathrm{pH} 8.0$ ) and then disrupted by soni- 
cation. The lysate was centrifuged for $1 \mathrm{~h}$ at $15,000 \times g$ and the supernatant was collected. To purify His-tagged Fha1 protein, the soluble fraction was loaded onto a Ni-NTA column (GE Healthcare, Piscataway, NJ, U.S.A.) preequilibrated with $1 \times$ PBS buffer. The Fha1 was eluted with $1 \times$ PBS buffer containing $500 \mathrm{mM}$ imidazole. The concentration of purified Fha1 was determined by the Bradford assay (Bradford 1976).

\section{Coimmunoprecipitation.}

To overexpress CaHIRI (Choi et al. 2011; Jung and Hwang 2007) in pepper plants, cMyc-tagged CaHIRl was cloned into the binary vector pBIN35S and transformed into the Agrobacterium tumefaciens GV3101. A. tumefaciens GV3101 containing empty vector or the pBIN35S:CaHIR1 construct was grown overnight at $28^{\circ} \mathrm{C}$ in yeast-peptone media (yeast extract at $10 \mathrm{~g} /$ liter, peptone at $10 \mathrm{~g} / \mathrm{liter}$, and $\mathrm{NaCl}$ [Difco, Detroit] at 5 g/liter, pH 7.5, adjusted with $\mathrm{NaOH}$ ) containing kanamycin (Kan) at $50 \mu \mathrm{g} \mathrm{ml}^{-1}$ and rifampicin (Rif) at $100 \mu \mathrm{g} \mathrm{ml}^{-1}$. The bacterial cells collected by centrifugation were suspended in infiltration buffer $(10 \mathrm{mM} \mathrm{MgCl}, 10 \mathrm{mM} 2-[\mathrm{N}$-morpholino] ethane sulfonic acid [pH 5.7], and $200 \mu \mathrm{M}$ acetosyringone) to a final $\mathrm{OD}_{600}$ of 0.5 and incubated for $1 \mathrm{~h}$ at room temperature. Bacterial suspensions were infiltrated into the abaxial side of pepper leaves with a needleless syringe. Total protein extracts were prepared by grinding $1 \mathrm{~g}$ of pepper leaf tissue in $2 \mathrm{ml}$ of lysis buffer (50 mM Tris- $\mathrm{HCl}$ [pH 7.5], $150 \mathrm{mM} \mathrm{NaCl}, 10 \mathrm{mM}$ EDTA, $0.2 \%$ Triton X-100, and complete protease inhibitor cocktail [Roche, Mannheim, Germany). Insoluble materials were pelleted by centrifugation at $20,000 \times g$ for $20 \mathrm{~min}$ at $4^{\circ} \mathrm{C}$. The supernatant $(500 \mu \mathrm{l})$ was combined with $100 \mu \mathrm{l}$ of resuspended anti-cMyc affinity matrix (Roche) with or without $1 \mu \mathrm{g}$ of His-tagged Fha1 protein. After incubation at $4^{\circ} \mathrm{C}$ overnight, the resins were washed four times with $1 \mathrm{ml}$ of lysis buffer and subjected to centrifugation at $15,000 \times g$ at $4^{\circ} \mathrm{C}$. The washed pellets were added with $200 \mu \mathrm{l}$ of electrophoresis sample buffer (20 mM Tris- $\mathrm{HCl}$ [pH 7.5], $2 \mathrm{mM}$ EDTA, 5\% sodium dodecyl sulfate [SDS], $0.02 \%$ bromophenol blue, $20 \%$ glycerol, and $200 \mathrm{mM}$ dithiothreitol), boiled for $5 \mathrm{~min}$, and then centrifuged at $15,000 \times g$ at $4^{\circ} \mathrm{C}$. Supernatant $(20 \mu \mathrm{l})$ was subjected to SDS-polyacrylamide gel electrophoresis and transferred to a polyvinylidene diflouride membrane for immunoblotting using anti-His antibody (Sigma-Aldrich, St. Louis).

\section{BiFC analyses.}

BiFC experiments were conducted as previously described (Choi et al. 2012; Walter et al. 2004). Briefly, the coding regions of fhal and CaHIRI were cloned into pSPYNE-35S and pSPYCE-35S. A. tumefaciens GV3101 carrying the BiFC constructs was coinfiltrated into the abaxial side of $N$. benthamiana leaves $\left(\mathrm{OD}_{600}=0.5\right.$ for each construct $)$. The epidermal cell layers were observed by confocal laser-scanning microscopy (LSM 5 Exciter) 1 and 2 days after agroinfiltration.

\section{Bacterial strains and growth conditions.}

E. coli $\mathrm{DH} 5 \alpha$ was cultured overnight in LB medium at $37^{\circ} \mathrm{C}$. X. campestris pv. vesicatoria Bv5-4a and mutant $\Delta$ fhal and $\Delta$ fhal (fhal) strains were cultured overnight in $\mathrm{YN}$ medium (yeast extract at $5 \mathrm{~g} \mathrm{liter}^{-1}$ and nutrient broth at $8 \mathrm{~g}$ liter $^{-1}$ ) at $28^{\circ} \mathrm{C}$. P. syringae pv. tomato $\mathrm{DC} 3000$ was grown overnight at $28^{\circ} \mathrm{C}$ on King's B medium (proteose peptone at $10 \mathrm{~g} \mathrm{liter}^{-1}, \mathrm{~K}_{2} \mathrm{HPO}_{4}$ at $1.5 \mathrm{~g} \mathrm{liter}^{-1}$, glycerol at $15 \mathrm{~g} \mathrm{liter}^{-1}$, and $5 \mathrm{mM} \mathrm{MgSO}_{4}, \mathrm{pH} 7.0$ ). Antibiotics used were Rif at $50 \mu \mathrm{g} \mathrm{ml}^{-1}$, Kan at $50 \mu \mathrm{g} \mathrm{ml}^{-1}$, and spectinomycin (Sp) at $50 \mu \mathrm{g} \mathrm{ml}^{-1}$.

\section{Site-directed mutagenesis and complementation.}

The 379-bp N-terminal fragment of fhal was amplified by PCR. The amplified fragment of fhal was digested with EcoRI and $X h o I$ and cloned into the pKnockout-G vector. The resulting plasmid was transformed into $E$. coli and used for triparental mating. The donor E. coli strain carrying pKnockoutG:fhal, helper E. coli strain carrying pRK2013, and recipient $X$. campestris pv. vesicatoria Bv5-4a were combined in a cell mixture and spread over YN agar plates without antibiotics (Windgassen et al. 2000). After overnight incubation at $28^{\circ} \mathrm{C}$, the exconjugants were washed from the plates and selected on YN agar medium supplemented with Rif and Sp at $50 \mu \mathrm{g} \mathrm{ml}^{-1}$ each. To complement the $\Delta$ fhal mutant, the genomic regions containing the $\mathrm{C}$-terminal regions of the gene encoding a hypothetical protein and full-length fhal were amplified by PCR. The amplified fragment was digested with EcoRI and cloned into the pVIK112 vector (Kalogeraki and Winans 1997). The resulting plasmid was transformed into E. coli and used for triparental mating, which was performed as described above using the $\Delta f h a l$ as a recipient strain.

\section{RT-PCR and quantitative real-time RT-PCR analyses.}

To examine the expression of fhal or plant $P R$ genes, total RNA was isolated from $X$. campestris pv. vesicatoria cells or plant tissues, respectively, using the TRIzol reagent according to the manufacturer's instructions (Invitrogen). After DNAse treatment, RT reactions were performed with total RNA $(2 \mu \mathrm{g})$ and oligo $\mathrm{p}(\mathrm{dN})_{6}$ primer at $42^{\circ} \mathrm{C}$ using AMV reverse transcriptase in a $20-\mu$ l reaction volume (Roche). To analyze the expression of fhal, aliquots $(1 \mu \mathrm{l})$ of RT reaction products were used for RT-PCR analysis. RT-PCR conditions were $95^{\circ} \mathrm{C}$ for $10 \mathrm{~min}$ and 30 cycles of $95^{\circ} \mathrm{C}$ for $30 \mathrm{~s}, 58^{\circ} \mathrm{C}$ for $30 \mathrm{~s}$, and $72^{\circ} \mathrm{C}$ for $1 \mathrm{~min}$. PCR products were analyzed by agarose gel electrophoresis to confirm the presence of single bands. The expression of plant $P R$ genes was examined by quantitative real-time RT-PCR. First-strand cDNA was diluted 1:10 with distilled water and used for real-time RT-PCR with iQ SYBR Green Supermix (Bio-Rad, Munich) using iCycler iQ (Bio$\mathrm{Rad}$ ). Tomato ACTIN and pepper $18 S$ rRNA were used as the internal controls to normalize $P R$ gene transcript levels.

\section{Adhesion assays.}

To examine the adhesion of cells to a plastic surface, overnight cultures of the $X$. campestris pv. vesicatoria, $\Delta$ fhal, and $\Delta$ fhal (fhal) strains in YN media were collected by centrifugation and resuspended in phosphate buffer $(\mathrm{pH} 7.0)$ to an $\mathrm{OD}_{660}$ of 0.6. Aliquots of $200 \mu \mathrm{l}$ of each bacterial suspension were transferred to each well of a 96-well PVC plate and incubated for $6 \mathrm{~h}$ at $28^{\circ} \mathrm{C}$. Bacterial adherence was measured by staining with $1 \% \mathrm{CV}$ for $15 \mathrm{~min}$ at room temperature after repetitive washing of the plate to remove nonadherent cells. Excess stain was removed by repetitive washing of the plate under running tap water. The CV stain was solubilized by the addition of 150 $\mu \mathrm{l}$ of $95 \%$ ethanol to each well and staining was quantified with a microplate reader at $570-\mathrm{nm}$ absorption wavelength. To measure the adherence of bacteria to the leaf surface of tomato and pepper plants, $20 \mu \mathrm{l}$ of each bacterial suspension collected from the abaxial side of leaves was incubated for $6 \mathrm{~h}$ at $28^{\circ} \mathrm{C}$ in a humidified chamber. Bacterial adhesion was measured by $\mathrm{CV}$ staining as described above.

\section{Plant materials and pathogen inoculation.}

Seed of pepper (C. annum L. 'Nockwang') and tomato (Solanum lycopersicon L. 'Kwang-bok') were germinated and grown in pots containing steam-sterilized soil mix (peat moss, perlite, and vermiculite; 5:3:2, vol/vol/vol) and loam soil (1:1, $\mathrm{vol} / \mathrm{vol})$ at $25^{\circ} \mathrm{C}$ with a photoperiod of $16 \mathrm{~h}$ of light and $8 \mathrm{~h}$ of darkness at a light intensity of $100 \mu \mathrm{mol}$ photons $\mathrm{m}^{-2} \mathrm{~s}^{-1}$.

WT and mutant $X$. campestris pv. vesicatoria strains were cultured overnight in $\mathrm{YN}$ broth at $28^{\circ} \mathrm{C}$. Prior to inoculation, 
bacterial cells were collected by centrifugation and resuspended in $10 \mathrm{mM} \mathrm{MgCl} 2$ solution $\left(10^{8} \mathrm{CFU} \mathrm{m}^{-1}\right)$. Bacterial suspensions were infiltrated into fully expanded leaves using a needless syringe. The infected plants were incubated at $28^{\circ} \mathrm{C}$ and harvested at various time points for bacterial growth assay.

\section{Generation of antibodies against Fha1.}

Rabbit polyclonal antibodies against the Fha1-specific peptide SVLNDSETNRYNSR were generated by AbFrontier (Seoul, Korea) and used to detect Fha1 proteins.

\section{Histochemical staining.}

Trypan blue and aniline blue staining were performed as previously described (Choi et al. 2011). To visualize the cell death response, leaves were stained with trypan blue and destained with a saturated chloral hydrate solution $\left(2.5 \mathrm{~g} \mathrm{ml}^{-1}\right)$. For aniline blue staining, leaves were cleared in alcoholic lactophenol (1 ml of lactic acid, $1 \mathrm{ml}$ of glycerol, $1 \mathrm{~g}$ of phenol, and $1 \mathrm{ml}$ of $\mathrm{H}_{2} \mathrm{O}$ ). Cleared leaves were stained with $0.01 \%$ aniline blue in $0.15 \mathrm{M}$ phosphate buffer, $\mathrm{pH}$ 9.5. Callose deposition was visualized with a fluorescence microscope under UV light (BH-2; Olympus, Tokyo).

For visualization of the nuclei, detached leaves were immersed in a staining solution (0.1\% DAPI in 5\% dimethyl sulfoxide [DMSO]). DAPI fluorescence images were obtained using excitation at $405 \mathrm{~nm}$ and emission at 435 to $480 \mathrm{~nm}$.

As a reliable tracer for endocytic trafficking, the lipophilic styryl dye FM4-64 (Invitrogen) was resuspended in DMSO to a concentration of $5 \mathrm{mM}$, diluted at 1:500 to 1:1000 in water, and infiltrated into the abaxial side of $N$. benthamiana leaves.

\section{Virus-induced gene silencing.}

The TRV-based virus-induced gene silencing system was used for gene silencing in pepper as described previously (Choi et al. 2013; Kim and Hwang 2011; Liu et al. 2002). The 225-bp 5' region of CaHIRl was amplified by PCR using specific primers and inserted into pTRV2 to generate TRV2: CaHIR1. A. tumefaciens GV3101 strains carrying pTRV1 or pTRV2 constructs were coinfiltrated into the fully expanded cotyledons of pepper (final $\mathrm{OD}_{600}=0.2$ for each construct). Plants were placed in a growth room at $25^{\circ} \mathrm{C}$ with a photoperiod cycle of $16 \mathrm{~h}$ of light and $8 \mathrm{~h}$ of darkness to allow growth and viral spread. Plants silenced for 4 to 5 weeks were used for pathogen inoculation.

\section{Arabidopsis transformation.}

The fhal coding region was PCR-amplified and cloned into the XbaI and BamHI sites of the binary vector pBIN35S (Choi and Hwang 2011). The resulting binary plasmid was transformed into Agrobacterium GV3101 by electroporation. The Agrobacterium-mediated transformation was performed using the floral-dipping method (Clough and Bent 1998). Transgenic plants were selected by germinating seed on Murashige and Skoog agar medium containing Kan at $50 \mu \mathrm{g} \mathrm{ml} \mathrm{m}^{-1}$.

\section{LITERATURE CITED}

Altenbach, D., and Robatzek, S. 2007. Pattern recognition receptors: From the cell surface to intracellular dynamics. Mol. Plant-Microbe Interact. 20:1031-1039.

Bent, A. F., and Mackey, D. 2007. Elicitors, effectors, and $R$ genes: The new paradigm and a lifetime supply of questions. Annu. Rev. Phytopathol. 45:399-436.

Bolte, S., Talbot, C., Boutte, Y., Catrice, O., Read, N.D., and SatiatJeunemaitre, B. 2004. FM-dyes as experimental probes for dissecting vesicle trafficking in living plant cells. J. Microsc. 214:159-173.

Bradford, M. M. 1976. A rapid and sensitive method for the quantitation of microgram quantities of protein utilizing the principle of protein-dye binding. Anal. Biochem. 72:248-254.
Browman, D. T., Hoegg, M. B., and Robbins, S. M. 2007. The SPFH domain-containing proteins: More than lipid raft markers. Trends Cell Biol. 17:394-402.

Chinchilla, D., Bauer, Z., Regenass, M., Boller, T., and Felix, G. 2006. The Arabidopsis receptor kinase FLS2 binds flg22 and determines the specificity of flagellin perception. Plant Cell 18:465-476.

Chisholm, S. T., Coaker, G., Day, B., and Staskawicz, B. J. 2006. Hostmicrobe interactions: Shaping the evolution of the plant immune response. Cell 124:803-814.

Choi, D. S., and Hwang, B. K. 2011. Proteomics and functional analyses of pepper abscisic acid-responsivel (ABR1), which is involved in cell death and defense signaling. Plant Cell 23:823-842.

Choi, D. S., Hwang, I. S., and Hwang, B. K. 2012. Requirement of the cytosolic interaction between pathogenesis-related protein 10 and leucine-rich repeat protein 1 for cell death and defense signaling in pepper. Plant Cell 24:1675-1690.

Choi, H. W., Kim, Y. J., Lee, S. C., Hong, J. K., and Hwang, B. K. 2007. Hydrogen peroxide generation by the pepper extracellular peroxidase $\mathrm{CaPO} 2$ activates local and systemic cell death and defense response to bacterial pathogens. Plant Physiol. 145:890-904.

Choi, H. W., Kim, Y. J., and Hwang, B. K. 2011. The hypersensitive induced reaction and leucine-rich repeat proteins regulate plant cell death associated with disease and plant immunity. Mol. Plant-Microbe Interact. 24:68-78.

Choi, H. W., Kim, N. H., Lee, Y. K., and Hwang, B. K. 2013. The pepper extracellular xyloglucan-specific endo- $\beta$-1,4-glucanase inhibitor protein gene, CaXEGIP1, is required for plant cell death and defense responses. Plant Physiol. 161:384-396.

Clough, S. H., and Bent, A. F. 1998. Floral dip: A simplified method for Agrobacterium-mediated transformation of Arabidopsis thaliana. Plant J. 16:735-743.

Cunnac, S., Wilson, A., Nuwer, J., Kirik, A., Baranage, G., and Mudgett, M. B. 2007. A conserved carboxylesterase is a SUPPRESSOR OF AVRBSTELICITED RESISTANCE in Arabidopsis. Plant Cell 19:688-705.

Felix, G., and Boller, T. 2003. Molecular sensing of bacteria in plants. The highly conserved RNA-binding motif RNP-1 of bacterial cold shock proteins is recognized as an elicitor signal in tobacco. J. Biol. Chem. 278:6201-6208.

Flor, H. H. 1971. Current status of the gene-for-gene concept. Annu. Rev. Phytopathol. 9:275-296.

Gadea, J., Mayda, M. E., Conejero, V., and Vera, P. 1996. Characterization of defense-related genes ectopically expressed in viroid-infected tomato plants. Mol. Plant-Microbe Interact. 9:409-415.

Gao, M., Wang, X., Wang, D., Xu, F., Ding, X., Zhang, Z., Bi, D., Cheng, Y. T., Chen, S., Li, X., and Zhang, Y. 2009. Regulation of cell death and innate immunity by two receptor-like kinases in Arabidopsis. Cell Host Microbe 6:34-44.

Goebel, E. M., Zhang, X., and Harvill, E. T. 2009. Bordetella pertussis infection or vaccination substantially protects mice against $B$. bronchiseptica infection. PLoS One 4:e6778.

Göhre, V., Spallek, T., Häweker, H., Mersmann, S., Mentzel, T., Boller, T., de Torres, M., Mansfield, J. W., and Robatzek, S. 2008. Plant patternrecognition receptor FLS2 is directed for degradation by the bacterial ubiquitin ligase AvrPtoB. Curr. Biol. 18:1824-1832.

Gómez-Gómez, L., Bauer, Z., and Boller, T. 2001. Both the extracellular leucine-rich repeat domain and the kinase activity of FSL2 are required for flagellin binding and signaling in Arabidopsis. Plant Cell 13:11551163

Gordon, S. 2002. Pattern recognition receptors: Doubling up for the innate immune response. Cell 111:927-930.

Gottig, N., Garavaglia, B. S., Garofalo, C. G., Orellano, E. G., and Ottado, J. 2009. A filamentous hemagglutinin-like protein of Xanthomonas axonopodis pv. citri, the phytopathogen responsible for citrus canker, is involved in bacterial virulence. PLoS One 4:e4358.

Guilhabert, M. R., and Kirkpatrick, B. C. 2005. Identification of Xylella fastidiosa antivirulence genes: Hemagglutinin adhesins contribute a biofilm maturation to $X$. fastidiosa and colonization and attenuate virulence. Mol. Plant-Microbe Interact. 18:856-868.

Ishibashi, Y., Claus, S., and Relman, D. A. 1994. Bordetella pertussis filamentous hemagglutinin interacts with a leukocyte signal transduction complex and stimulates bacterial adherence to monocyte CR3 (CD11b/CD18). J. Exp. Med. 180:1225-1233.

Jones, J. D. G., and Dangl, J. L. 2006. The plant immune system. Nature 444:323-329.

Jung, E. H., Jung, H. W., Lee, S. C., Han, S. W., Heu, S., and Hwang, B. K. 2004. Identification of a novel pathogen-induced gene encoding a leucine-rich repeat protein expressed in phloem cells of Capsicum annum. Biochim. Biophys. Acta. 1676:211-222.

Jung, H. W., and Hwang, B. K. 2007. The leucine-rich repeat (LRR) protein, CaLRR1, interacts with the hypersensitive induced reaction (HIR) 
protein, CaHIR1, and suppresses cell death induced by CaHIR1 protein. Mol. Plant Pathol. 8:503-514.

Jung, H. W., Lim, C. W., Lee, S. C., Choi, H. W., Hwang, C. H., and Hwang, B. K. 2008. Distinct roles of the pepper hypersensitive induced reaction protein gene $C a H I R 1$ in disease and osmotic stress, as determined by comparative transcriptome and proteome analyses. Planta 227:409-425

Kajava, A. V., Cheng, N., Cleaver, R., Kessel, M., Simon, M. N., Willery, E., Jacob-Dubuisson, F., Locht, C., and Steven, A. C. 2001. Beta-helix model for the filamentous haemagglutinin adhesin of Bordetella pertussis and related bacterial secretory proteins. Mol. Microbiol. 42:279-292.

Kalogeraki, V. S., and Winans, S. C. 1997. Suicide plasmids containing promoterless reporter genes can simultaneously disrupt and create fusions to target genes of diverse bacteria. Gene 188:69-75.

Kang, H. G., Oh, C. S., Sato, M., Katagiri, F., Glazebrook, J., Takahashi, H., Kachroo, P., Martin, G. B., and Klessig, D. F. 2010. Endosomeassociated CRT1 functions early in resistance gene-mediated defense signaling in Arabidopsis and tobacco. Plant Cell 22:918-936.

Kankanala, P., Czymmek, K., and Valent, B. 2007. Roles for rice membrane dynamics and plamodesmata during biotrophic invasion by the blast fungus. Plant Cell 19:706-724.

Kim, D. S., and Hwang, B. K. 2011. The pepper receptor-like cytoplasmic protein kinase CaPIK1 is involved in plant signaling of defense and cell-death responses. Plant J. 66:642-655.

Kim, N. H., Choi, H. W., and Hwang, B. K. 2010. Xanthomonas campestris pv. vesicatoria effector AvrBsT induces cell death in pepper, but suppresses defense responses in tomato. Mol. Plant-Microbe Interact. 23:1069-1082.

Klarzynski, O., Plesse, B., Joubert, J. M., Yvin, J. C., Kopp, M., Kloareg, B., and Fritig, B. 2000. Linear beta-1,3 glucans are elicitors of defense responses in tobacco. Plant Physiol. 124:1027-1038.

Kunze, G., Zipfel, C., Robatzek, S., Niehaus, K., Boller, T., and Felix, G. 2004. The $\mathrm{N}$ terminus of bacterial elongation factor Tu elicits innate immunity in Arabidopsis plants. Plant Cell 16:3496-3507.

Link, S., Schmitt, K., Beier, D., and Gross, R. 2007. Identification and regulation of expression of a gene encoding a filamentous hemagglutininrelated protein in Bordetella holmesii. BMC Microbiol. 7:100.

Liu, Y., Schiff, M., and Dinesh-Kumar, S. P. 2002. Virus-induced gene silencing in tomato. Plant J. 31:777-786.

Locht, C., Antoine, R., and Jacob-Dubuisson, F. 2001. Bordetella pertussis, molecular pathogenesis under multiple aspects. Curr. Opin. Microbiol. 4:82-89.

Mobberley-Schuman, P. S., and Weiss, A. A. 2005. Influence of CR3 (CD11b/CD18) expression on phagocytosis of Bordetella pertussis by human neutrophils. Infect. Immun. 73:7317-7323.

Nürnberger ,T., Brunner, F., Kemmerling, B., and Piater, L. 2004. Innate immunity in plants and animals: Striking similarities and obvious differences. Immunol. Rev. 198:249-266.

Qi, Y., and Katagiri, F. 2012. Membrane microdomain may be a platform for immune signaling. Plant Signal Behav. 7:454-456.
Qi, Y., Tsuda, K., Nguyen, le V., Wang, X., Lin, J., Murphy, A. S , Glazebrook, J., Thordal-Christensen, H., and Katagiri, F. 2011. Physical association of Arabidopsis hypersensitive induced reaction proteins (HIRs) with the immune receptor RPS2. J. Biol. Chem. 286:312973307

Relman, D., Tuomanen, E., Falkow, S., Golenbock, D. T., Saukkonen, K., and Wright, S. D. 1990. Recognition of a bacterial adhesion by an integrin: Macrophage CR3 $\left(\alpha_{M} \beta_{2}\right.$, CD11b/CD18) binds filamentous hemagglutinin of Bordetella pertussis. Cell 61:1375-1382.

Rieber, N., Graf, A., Belohradsky, B. H., Hartl, D., Urschel, S., Riffelmann, M., Wirsing von König, C. H., and Liese, J. 2008. Differences of humoral and cellular immune response to an acellular pertussis booster in adolescents with a whole cell or acellular primary vaccination. Vaccine 26:6929-6935.

Robatzek, S., Chinchilla, D., and Boller, T. 2006. Ligand-induced endocytosis of the pattern recognition receptor FLS2 in Arabidopsis. Genes Dev. 20:537-542.

Rojas, C. M., Ham, J. H., Deng, W. L., Doyle, J. J., and Collmer, A. 2002 HecA, a member of a class of adhesins produced by diverse pathogenic bacteria, contributes to the attachment, aggregation, epidermal cell killing, and virulence phenotypes of Erwinia chrysanthemi EC16 on Nicotiana clevelandii seedlings. Proc. Natl. Acad. Sci. U.S.A. 99:13142 13147.

van den Heuvel, K. J., Hulzink, J. M., Barendse, G. W., and Wullems, G. J. 2001. The expression of tgas 118 , encoding a defensin in Lycopersicon esculentum, is regulated by gibberellin. J. Exp. Bot. 52:1427-1436.

Walter, M., Chaban, C., Schütze, K., Batistic, O., Weckermann, K., Näke, C., Blazevic, D., Grefen, C., Schumacher, K., Oecking, C., Harter, K., and Kudla, J. 2004. Visualization of protein interactions in living plant cells using bimolecular fluorescence complementation. Plant J. 40:428438.

Weingart, C. L., and Weiss, A. A. 2000. Bordetella pertussis virulence factors affect phagocytosis by human neutrophils. Infect. Immun. 68:17351739

Windgassen, M., Urban, A., and Jaeger, K. E. 2000. Rapid gene inactivation in Pseudomonas aeruginosa. FEMS (Fed. Eur. Microbiol. Soc.) Microbiol. Lett. 193:201-215.

Zipfel, C. 2008. Pattern-recognition receptors in plant innate immunity. Curr. Opin. Immunol. 20:10-16.

Zipfel, C., and Felix, G. 2005. Plants and animals: A different taste for microbes? Curr. Opin. Plant Biol. 8:353-360.

Zipfel, C., Kunze, G., Chinchilla, D., Caniard, A., Jones, J. D., Boller, T., and Felix, G. 2006. Perception of the bacterial PAMP EF-Tu by the receptor EFR restricts Agrobacterium-mediated transformation. Cell 125:749-760.

\section{AUTHOR-RECOMMENDED INTERNET RESOURCE}

PSORTb prediction tool: www.psort.org/psortb 